\title{
A novel multi-functionalized multicellular nanodelivery system for non-small cell lung cancer photochemotherapy
}

\author{
Yongtai Zhang ${ }^{1 \dagger}$, Qing Xia ${ }^{1 \dagger}$, Tong $\mathrm{Wu}^{1 \dagger}$, Zehui He${ }^{1}$, Yanyan $\mathrm{Li}^{1}$, Zhe $\mathrm{Li}^{1}$, Xuefeng Hou' ${ }^{1}$, Yuanzhi He${ }^{1}$,
} Shuyao Ruan', Zhi Wang ${ }^{1}$, Jia Sun ${ }^{2}$ and Nianping Feng ${ }^{1 *}$ (B)

\begin{abstract}
Background: A red blood cell membrane (RBCm)-derived drug delivery system allows prolonged circulation of an antitumor treatment and overcomes the issue of accelerated blood clearance induced by PEGylation. However, RBCm-derived drug delivery systems are limited by low drug-loading capacities and the lack of tumor-targeting ability. Thus, new designs of RBCm-based delivery systems are needed.
\end{abstract}

Results: Herein, we designed hyaluronic acid (HA)-hybridized RBCm (HA\&RBCm)-coated lipid multichambered nanoparticles (HA\&RBCm-LCNPS) to remedy the limitations of traditional RBCm drug delivery systems. The inner core co-assembled with phospholipid-regulated glycerol dioleate/water system in HA\&RBCm-LCNPs met the required level of blood compatibility for intravenous administration. These newly designed nanocarriers had a honeycomb structure with abundant spaces that efficiently encapsulated paclitaxel and IR780 for photochemotherapy. The HA\&RBCm coating allowed the nanocarriers to overcome the reticuloendothelial system barrier and enhanced the nanocarriers specificity to A549 cells with high levels of CD44. These properties enhanced the combinatorial antitumor effects of paclitaxel and IR780 associated with microtubule destruction and the mitochondrial apoptotic pathway.

Conclusions: The multifunctional HA\&RBCm-LCNPs we designed expanded the functionality of RBCm and resulted in a vehicle for safe and efficient antitumor treatment.

Keywords: Photodynamic therapy, Red blood cell, Biomimetic, Nanoparticles, Liposomes, Tumor

\section{Background}

Lung cancer has been associated with the highest mortality rate among all cancers in 2020 worldwide [1]. Currently, pharmacotherapy remains the primary treatment strategy against lung cancer. However, owing to difficulties in the delivery of traditional drug preparations to the tumor tissue, medications are frequently administered, thereby increasing the incidence of toxic side effects.

\footnotetext{
*Correspondence: npfeng@hotmail.com; npfeng@shutcm.edu.cn

${ }^{\dagger}$ Yongtai Zhang, Qing Xia and Tong Wu contributed equally to this work

${ }^{1}$ Department of Pharmaceutical Sciences, Shanghai University

of Traditional Chinese Medicine, Shanghai 201203, China

Full list of author information is available at the end of the article
}

Nanocarriers are widely employed in tumor therapy research for their ability to accumulate in tumors and their controlled drug-release properties [2]. Among various nanocarriers, biomimetic nanoparticles have received great attention [3-5]. For successful drug delivery to tumor tissues, a drug construct must not be eliminated by the reticuloendothelial system (RES) and should achieve prolonged circulation in the blood $[6,7]$. A common method for extending the retention time of therapeutics in the blood is through the use of stealth nanoparticles camouflaged with polyethylene glycol (PEG), which increases the hydrophilicity of the constructs and allows escape from RES phagocytosis [8]. However, although PEGylation prolongs the circulation original author(s) and the source, provide a link to the Creative Commons licence, and indicate if changes were made. The images or other third party material in this article are included in the article's Creative Commons licence, unless indicated otherwise in a credit line to the material. If material is not included in the article's Creative Commons licence and your intended use is not permitted by statutory regulation or exceeds the permitted use, you will need to obtain permission directly from the copyright holder. To view a copy of this licence, visit http://creativecommons.org/licenses/by/4.0/. The Creative Commons Public Domain Dedication waiver (http://creativeco mmons.org/publicdomain/zero/1.0/) applies to the data made available in this article, unless otherwise stated in a credit line to the data. 
of nanoparticles, PEG overexposure leads to antiPEG IgG production, which induces humoral immune response and RES phagocytosis $[9,10]$. As this is typically followed by an accelerated blood clearance, the clinical application of PEGylated nanocarriers remains a challenge [11].

In recent years, cell membrane-derived biomimetic nanocarriers have been used to extend the circulation and to facilitate tumor accumulation of drugs [12]. These nanocarriers are derived from bacteria, cancer cells, stem cells, lymphocytes, platelets, white blood cells, and red blood cells (RBCs). RBC membranes (RBCm) have been used as nanocarriers since the mid-1990 s [13]. Compared to PEGylated nanoparticles, $\mathrm{RBCm}$ have various advantages, including ease of availability, an endogenous nature, and low immunogenicity [14-17]. However, $\mathrm{RBCm}$ lack tumor-specific adhesion molecules and have low drug-loading capacity. The reliability of passive tumor-targeted drug delivery using nanoparticles with enhanced permeability and retention (EPR) remains controversial [18]. Therefore, $\mathrm{RBCm}$ nanocarriers require structural modifications to increase their ability to deliver drugs into tumor tissues [19].
Lipid multi-chamber nanoparticles (LCNPs), such as cubosomes, multilayered liposomes, and multichamber liposomes have been widely used as delivery vehicles for various drugs due to their excellent drug-loading properties [20-22]. In this study, RBCm-coated phospholipid-mediated LCNPs (RBCm-LCNPs) possessing honeycomb or spongy structures biocompatible with intravenous administration, were used as carriers for co-loading paclitaxel (PTX) and the near-infrared dye, IR780, to achieve extended circulation and combined chemotherapy and phototherapy. To enhance the tumor accumulation of the vector based on the high expression of the CD44 protein in human non-small cell lung cancer cells (A549), hyaluronic acid (HA), a natural receptor for CD44 that exerts good biocompatibility, biodegradability, and non-immunogenicity properties, was selected to hybridize $\mathrm{RBCm}$ (HA\&RBCm) [23-25]. In the present study, we investigated the circulation, the mechanism, and the potential value of this new drug delivery system in combinatorial tumor photochemotherapy (Fig. 1).
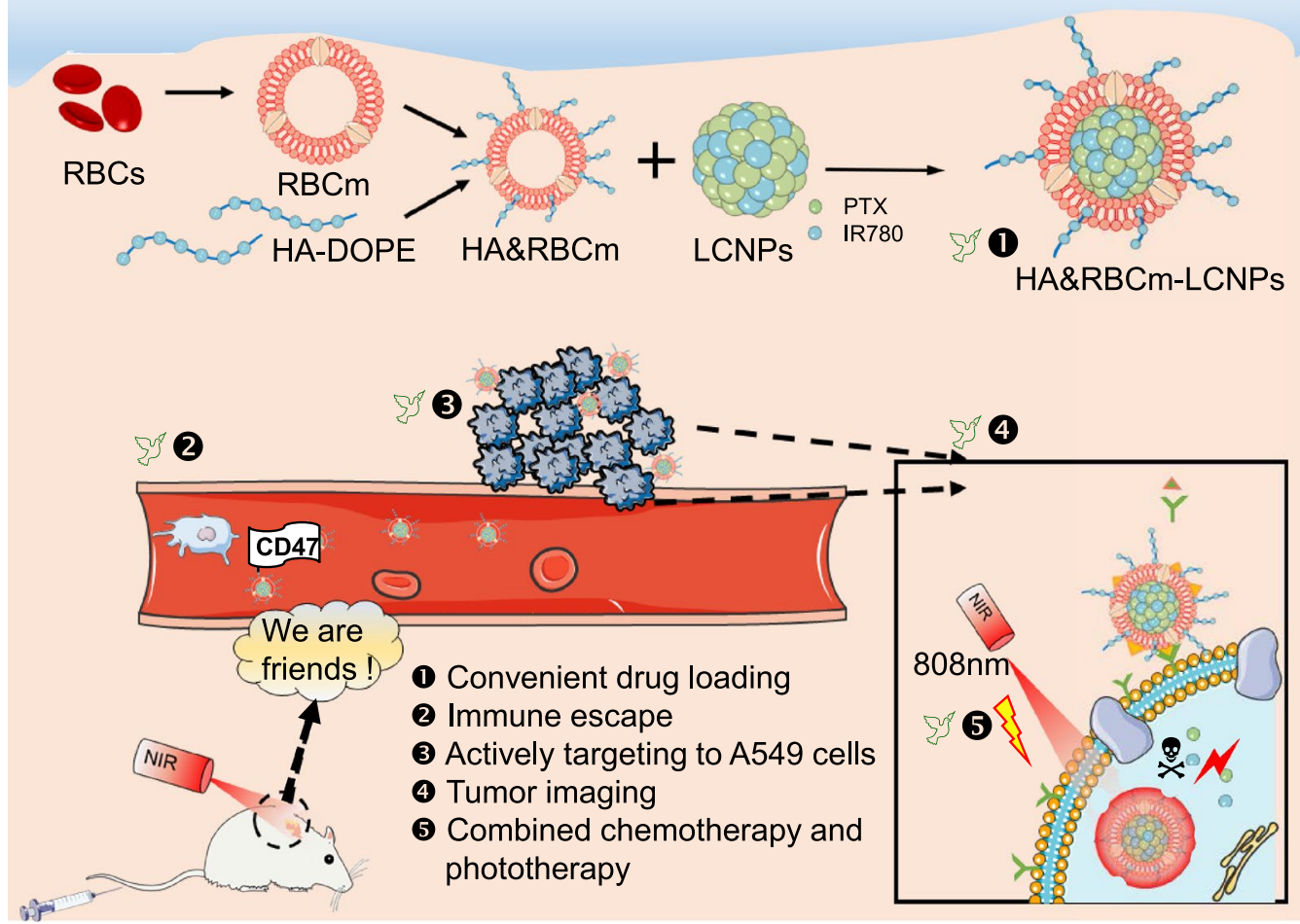

Fig. 1 Schematic illustration of the preparation of HA\&RBCm-LCNPS, its prolonged circulation in the blood, and its ability to actively target A549 cells for photochemotherapy of tumors 


\section{Results and discussion}

\section{Characterization of the preparations}

In recent years, the most studied system for LCNPs formulation has been the glycerol monooleate/water system, which is valued for its remarkable stability, simple and green manufacturing process, and low material cost. However, unsaturated monoglyceride causes hemolysis in animals; thus, this system is not suitable for intravenous administration [26, 27]. Therefore, in this study, we prepared LCNPs using a biocompatible, phospholipidregulated glycerol dioleate/water system suitable for injection (Fig. 2).

As the normal thickness of RBCm was 7 to $8 \mathrm{~nm}$, the increase in particle size of RBCm-LCNPs was attributed to the lipid bilayer of $\mathrm{RBCm}$. After modification with HA-conjugated dioleoyl phosphoethanolamine (HADOPE), the particle size increased to $220 \mathrm{~nm}$ (Additional file 1: Figure S1A). The increase in the negative charge of RBCm-LCNPs relative to non-coated LCNPs improved nanoparticle stability in the blood [28, 29]. LCNPs appeared round, showed uniform morphology and distribution, and were non-adhesive. After the cell membrane was coated, a clear core-membrane structure was observed (Fig. 2B). The LCNPs had a honeycomb or sponge-like internal structure, which showed no significant changes after cell membrane coating (Fig. 2C). The drug-loading and encapsulation efficiencies of the nanocarriers were 8.7 and 95\% for PTX, respectively, and 1.7 and $93 \%$ for IR780, respectively. Thus, the multichambered structure of LCNP we produced had excellent drug-loading.

The prolonged circulation of RBCs in the blood is mediated by specific membrane proteins [30]. Most RBCm proteins, including $\mathrm{CD} 47$, were retained on $\mathrm{RBCm}$ LCNPs and HA\&RBCm-coated LCNPs (HA\&RBCmLCNPs) (Fig. 2D). CD47 is a self-marker protein that actively signals macrophages [31]. The signal-regulated protein alpha glycoprotein expressed by phagocytic cells, recognizes CD47 as a "don't eat me" signal to prevent immune cells from inducing $\mathrm{RBC}$ phagocytosis [32, 33].

No significant change in particle size of LCNPs and $\mathrm{RBCm}$-coated nanoparticles was found in the plasma for $72 \mathrm{~h}$ (Additional file 1: Figure S1B), which suggests potential for long circulation of the nanocarriers in the blood. No precipitation and aggregation were found in the blood, and there was no hemolysis in the range of 0.5-50 $\mu \mathrm{g} / \mathrm{mL}$ (PTX) for RBCm-LCNPs and HA\&RBCmLCNPs; in contrast, precipitation, aggregation, and hemolysis were observed in the saline group (Additional file 1: Figure S1C). These findings imply that the blood compatibility of LCNPs were improved by RBCm and HA\&RBCm coating; therefore, these systems were deemed suitable for intravenous administration. The cumulative in vitro release of both PTX and IR780 from LCNPs for 72 h were about $80 \%$, and both systems exhibited synchronous release. After being coated with $\mathrm{RBCm}$ and being modified with HA, the degree of sustained release was more significant (Additional file 1: Figure S2). Sustained release has been reported to be associated with the prolonged circulation time of the loaded hydrophobic drug in the blood [34].

The maximum absorption wavelength of IR780 in the nanoparticle group was slightly higher (red shift) than that of IR780 in solution (Additional file 1: Figure S3A), which may be induced by the increase of internal stress, decrease of energy gap, and vacancy effect caused by the nanocarriers, suggesting that IR780 was successfully encapsulated in LCNPs. IR780 quenching was faster when the particles were exposed to normal light than when protected from light, and quenching slowed down following encapsulation by nanoparticles. HA\&RBCmLCNPs showed better protection of IR780 than LCNPs (Additional file 1: Figure S3B-D). When irradiated with near-infrared (NIR) light $(808 \mathrm{~nm})$, the quenching of IR780 in the HA\&RBCm-LCNP group was slower than that in the LCNP group, but IR780 in both groups was completely quenched $5 \mathrm{~min}$ post-exposure (Additional file 1: Figure S3E). Therefore, the NIR exposure time was set to $5 \mathrm{~min}$ in subsequent phototherapy experiments. The IR780-loaded nanocarriers in aqueous solution exhibited a gradual dose-dependent increase in temperature following NIR irradiation (Fig. 3A). At an IR780 concentration of $60 \mu \mathrm{g} / \mathrm{mL}$, the water temperature increased to above $45{ }^{\circ} \mathrm{C}$ within $5 \mathrm{~min}$, but at low concentration $(20 \mu \mathrm{g} / \mathrm{mL})$, the water temperature did not exceed $37{ }^{\circ} \mathrm{C}$. Although it was difficult to achieve photothermal effects at low concentrations, we found that even at very low concentrations of IR780 $(0.1 \mu \mathrm{g} / \mathrm{mL})$, the fluorescence intensity of Singlet Oxygen Sensor Green ${ }^{\circledR}$ (SOSG) generated after NIR irradiation for only $10 \mathrm{~s}$ was much greater than those of the control (water) and nonNIR-treated groups $(p<0.0001)$, suggesting that IR780 induced the production of a large amount of singlet oxygen, and the yield grew over a prolonged duration and increased IR780 concentration (Fig. 3B). These results demonstrate that PTX/IR780-HA\&RBCm-LCNPs have excellent photodynamic effects.

\section{In vitro cellular uptake}

To determine the tumor accumulation potential of nanocarriers and their stealth properties in the blood, tumor cells (A549) with high expression levels of CD44 as a primary receptor for the macromolecule HA, and macrophages with RES phagocytic function (RAW264.7) were observed for their ability to take up the nanocarriers involved in this study. Although the uptake of IR780 and 


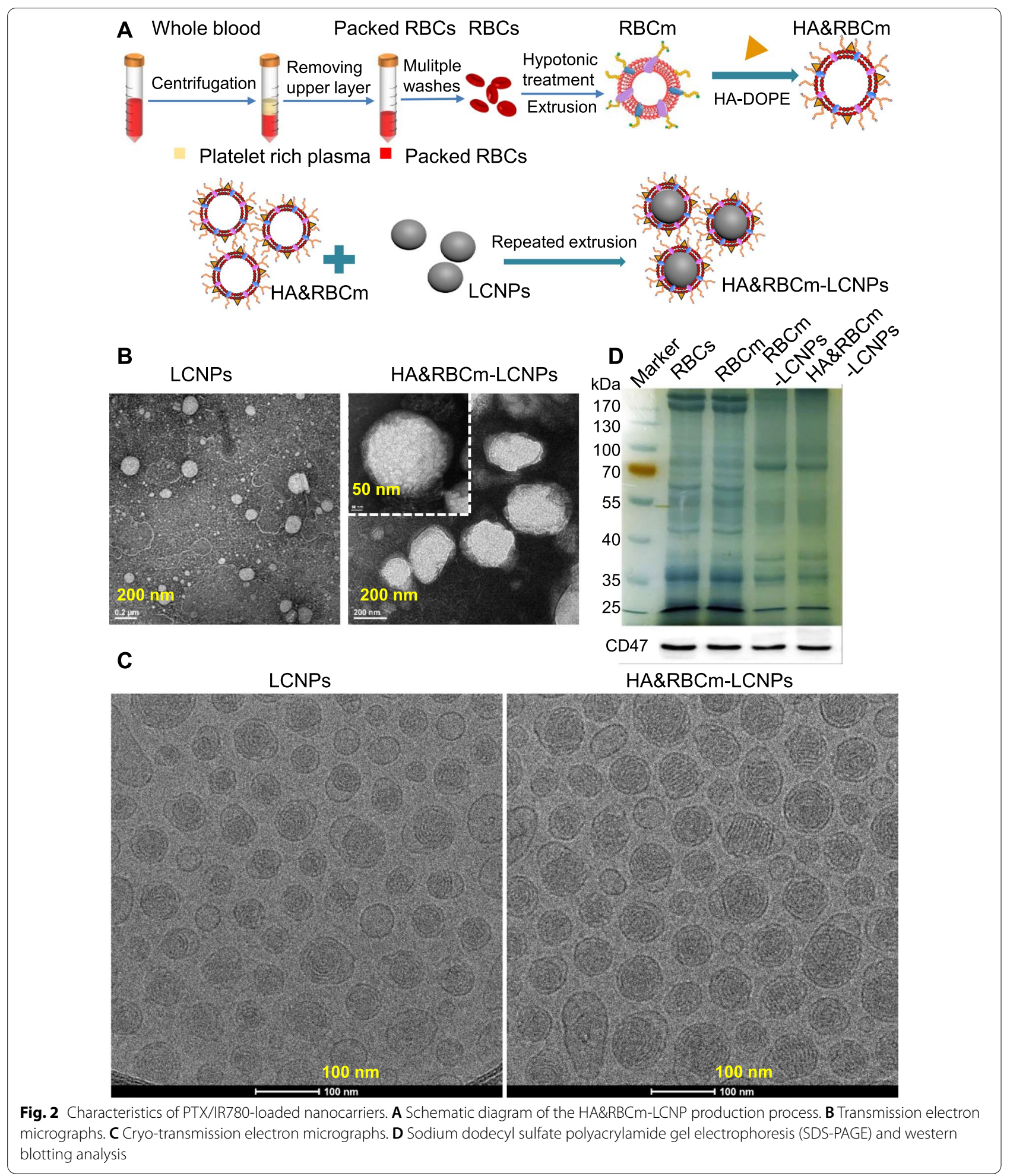

paclitaxel by cells was not measured, the ability of different nanocarriers to be internalized by cells was successfully evaluated using $\mathrm{C} 6$ as a fluorescent probe. Even at a very low final concentration of C6 in the medium $(1 \mu \mathrm{g} /$ $\mathrm{mL})$, the C6 fluorescence in the cells was very strong after being incubated with C6-encapsulated nanocarriers 
A

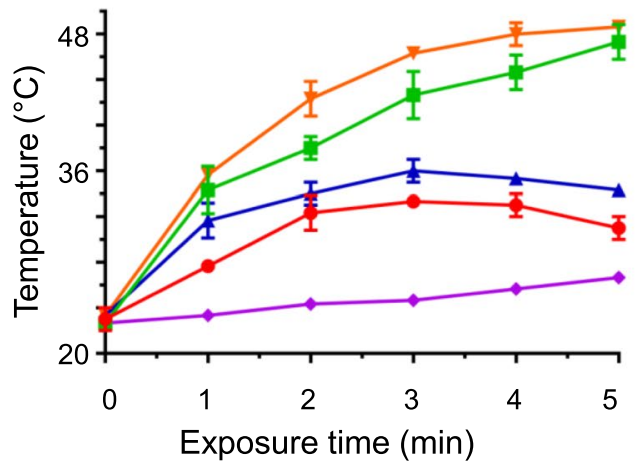

$\rightarrow$ PTX/IR780-HA\&RBCm-LCNPs

(PTX, $100 \mu \mathrm{g} / \mathrm{mL}$; IR780, $20 \mu \mathrm{g} / \mathrm{mL}$ )

-PTX/IR780-HA\&RBCm-LCNPs

(IPTX, $300 \mu \mathrm{g} / \mathrm{mL}$; R780, $60 \mu \mathrm{g} / \mathrm{mL}$ )

† PTX/IR780-LCNPs

(PTX, $100 \mu \mathrm{g} / \mathrm{mL}$; IR780, $20 \mu \mathrm{g} / \mathrm{mL}$ )

\# PTX/IR780-LCNPs

(PTX, $300 \mu \mathrm{g} / \mathrm{mL}$; R780, $60 \mu \mathrm{g} / \mathrm{mL}$ )

$\rightarrow$ Water
B

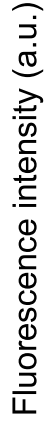

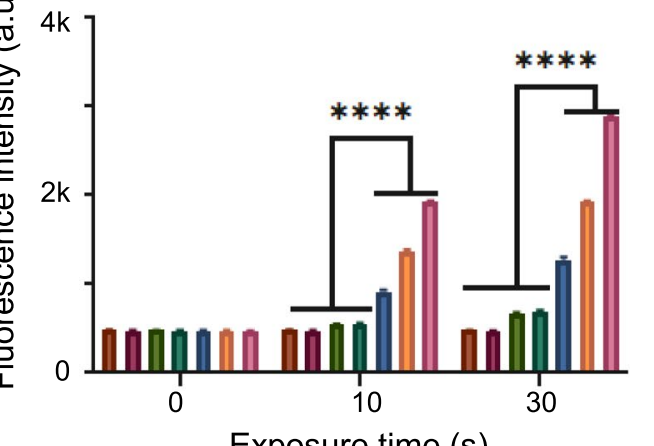

$4 \mathrm{k}$

Control

- Blank HA\&RBCm-LCNPs

- PTX-HA\&RBCm-LCNPs (PTX, $10 \mu \mathrm{g} / \mathrm{mL}$ )

- PTX/IR780-HA\&RBCm-LCNPs

(PTX, $10 \mu \mathrm{g} / \mathrm{mL}$; IR780, $2 \mu \mathrm{g} / \mathrm{mL}$ )

- PTX/IR780-HA\&RBCm-LCNPs+NIR

(PTX, $0.5 \mu \mathrm{g} / \mathrm{mL}$; IR780, $0.1 \mu \mathrm{g} / \mathrm{mL}$ )

- PTX/IR780-HA\&RBCm-LCNPs+NIR

(PTX, $5.0 \mu \mathrm{g} / \mathrm{mL}$; IR780, $1.0 \mu \mathrm{g} / \mathrm{mL}$ )

- PTX/IR780-HA\&RBCm-LCNPs+NIR

(PTX, $10.0 \mu \mathrm{g} / \mathrm{mL} ; \mathrm{IR} 780,2.0 \mu \mathrm{g} / \mathrm{mL}$ )

Fig. 3 Photothermal and photodynamic characteristics of PTX/IR780-loaded nanocarriers. A heating profiles of the water and nano-formulation solutions following near-infrared irradiation (NIR: $808 \mathrm{~nm}, 1 \mathrm{~W} / \mathrm{cm}^{2}$ ). B the fluorescence intensity of SOSG in water (Control) and nano-formulation solutions $(\mathrm{n}=3) .{ }^{* * * *} p<0.0001$

for $2 \mathrm{~h}$, resulting in the fluorescence-activated cell sorting (FACS) signal peaks were not completely separated (Fig. 4A), but the statistical results of the fluorescence intensity of each test group showed that there were extremely significant differences between different nanocarriers. The fluorescence intensity of A549 cells in the RBCm-LCNP group was lower than that in the LCNP group, which could be attributed to the increased interaction between the nanoparticles and the cells, owing to the increased negative charge on the surface of RBCmcoated LCNPs. Following HA modification, cellular uptake of nanoparticles substantially increased. The fluorescence intensity in the HA\&RBCm-LCNP (HADOPE: $0.5 \mathrm{mg} / \mathrm{mL}$ ) group was 1.87 -fold higher than that in the RBCm-LCNP group. However, cellular uptake of the RBCm-LCNPs modified with different HA-DOPE concentrations $(0.5 \mathrm{mg} / \mathrm{mL}$ and $1.0 \mathrm{mg} / \mathrm{mL})$ at the point where CD44 was saturated with HA did not significantly differ $(p>0.05)$. Moreover, the fluorescence intensity in the HA\&RBCm-LCNP group with free HA-DOPE was markedly lower than that in the two HA\&RBCm-LCNP groups with no free HA-DOPE competitively bound to the CD44 receptor of A549 cells $(p<0.0001)$. Considering that using a large number of cells may yield false negative results in FACS, the nanocarriers internalized by cells were further visualized via confocal laser scanning microscopy (CLSM). Post-incubation with the coumarin 6 (C6)-labeled preparation showed that green fluorescence of $\mathrm{C} 6$ was primarily distributed in the cell membrane and the cytoplasm, and no signal was observed in the 4',6-diamidino-2-phenylindole (DAPI)labeled nucleus with blue fluorescence (Fig. 4A). CLSM imaging also showed that the fluorescence intensity in the RBCm-LCNP group was remarkably lower than that in the LCNP group, whereas that in the HA\&RBCmLCNP group was markedly higher. These results correspond with the results of the flow cytometric analysis and confirmed that HA\&RBCm-LCNP actively target A549 cells.

Escaping phagocytosis by macrophages is a key factor for the extended circulation of nanoparticles in the blood. RBCm-coated nanoparticles reduced the rate of macrophage phagocytosis, as shown by a notable decrease in the RAW264.7 cell uptake of RBCm-coated 
A 1

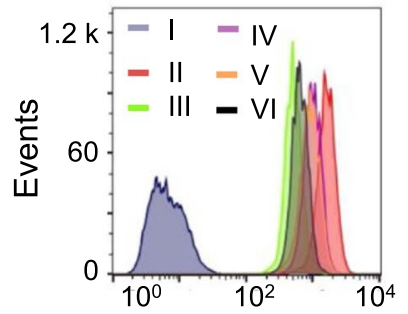

广்



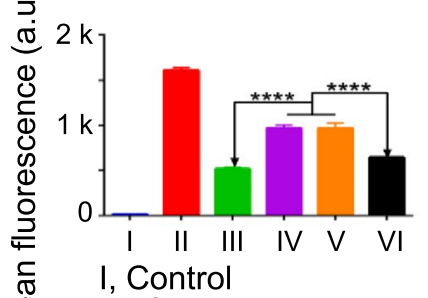

$\stackrel{\infty}{\infty}$ II, LCNPS

III, RBCm-LCNPs

IV, HA\&RBCm-LCNPs-1

$V$, HA\&RBCm-LCNPs-2

B

VI, With free HA-DOPE
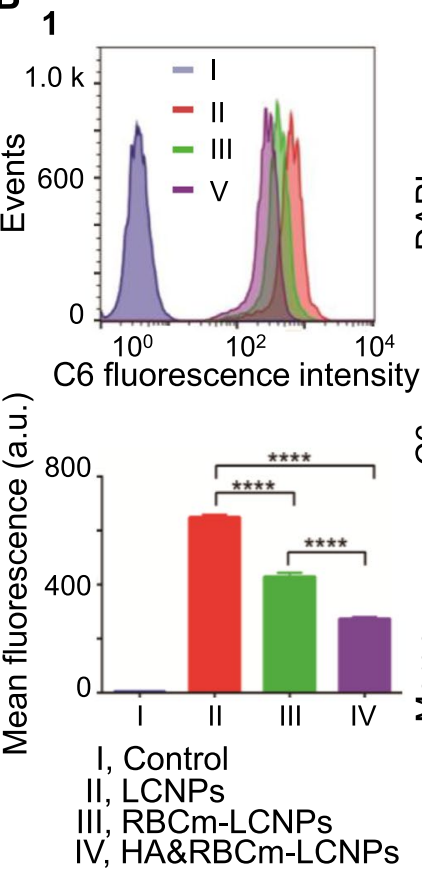

2

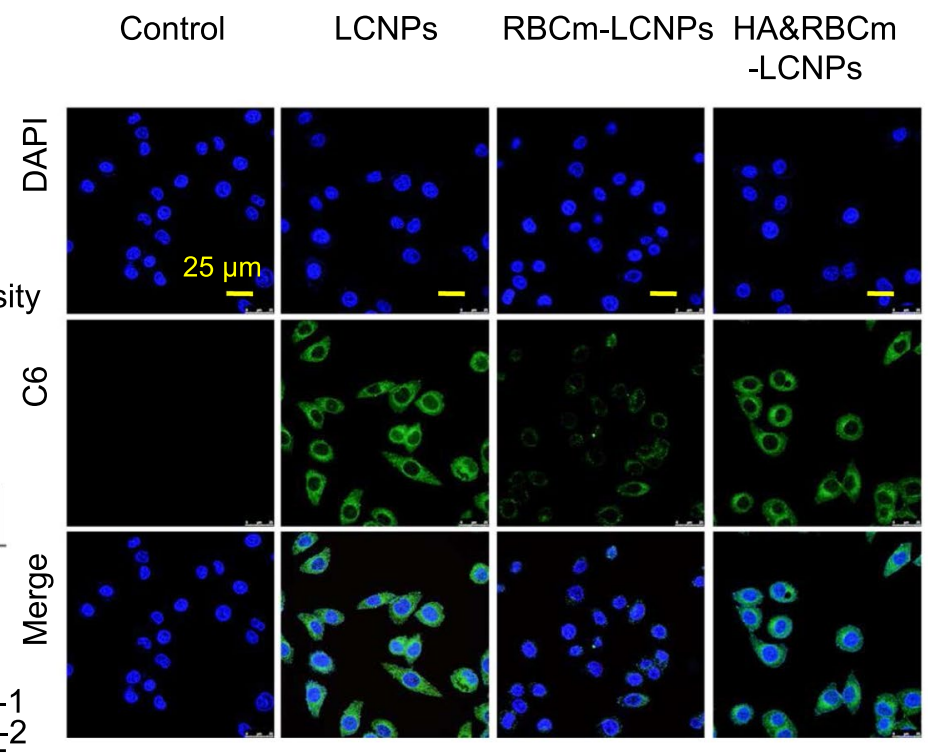

2

-LCNPS
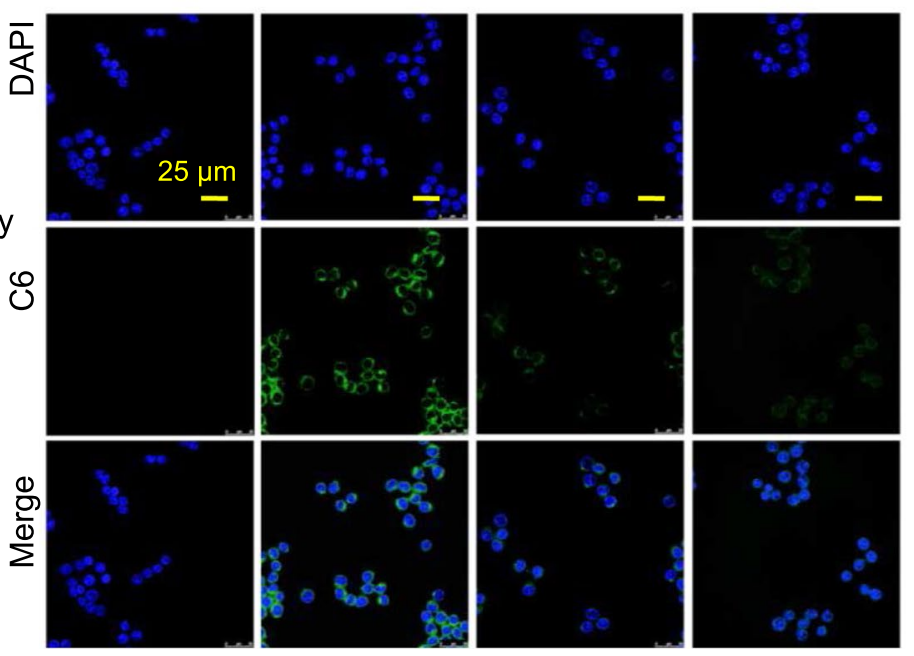

Fig. 4 Uptake of C6-labeled nanocarriers by A A549 and B RAW264.7 cells. HA\&RBCm-LCNPs-1 and -2 refer to LCNPs with HA-DOPE concentrations of 0.5 and $1.0 \mathrm{mg} / \mathrm{mL}$, respectively. The "Control" group represents untreated cells; the "with free HA-DOPE" group was administered HA\&RBCm-LCNPs without the removal of free HA-DOPE during the final process. Analysis was performed through flow cytometry (1; top, FACS analysis of the C6 signal; bottom, statistical analysis of differences in the fluorescence intensity among the groups) and confocal laser scanning microscopy $\left(2\right.$; nucleus was labeled with DAPI) $(n=3) .{ }^{* * *} p<0.0001$

nanoparticles compared to that of LCNPs without RBCm coating $(p<0.0001)$ (Fig. $4 \mathrm{~B})$. Furthermore, HA modification masked the $\mathrm{RBCm}$-uncoated regions of the nanoparticles, improved the sustained release of the liposoluble cargo (C6), which resulted in a highly significant reduction in the uptake of HA\&RBCm-LCNPs [35]. After ingestion by RAW264.7 cells, C6 was primarily distributed in the cell membrane and cytoplasm and 
did not accumulate in the nucleus. The weakest fluorescence signals detected through CLSM were observed in the HA\&RBCm-LCNP group. The successful transfer of $\mathrm{RBCm}$ proteins, such as CD47, to the LCNPs is key for weakening the immune response by presenting drugloaded nanocarriers as "self," ultimately leading to longterm circulation of LCNPs in the blood [36, 37].

\section{In vitro antitumor effects}

Photochemotherapy produced by the combination of PTX and IR780 has been shown to enhance antitumor effects [38]. For example, the cure rate of primary melanoma-bearing mice with intratumoral injection was $100 \%$ within 30 days [39]; IR780 was able to exert photothermal therapeutic effects on pancreatic ductal adenocarcinoma and expanded the tumor interstitial space to promote paclitaxel delivery to deep tumor tissues [40]. However, IR780 is a NIR-I near-infrared photosensitizer with a limited tissue-penetrating depth [41]. As a result, photothermal therapy administered via intravenous injection generally requires a higher dose than local administration (for mice, the intravenous dose generally exceeds $1 \mathrm{mg}$ / $\mathrm{kg}$ ) (Additional file 1: Table S1) and requires coupling with high-intensity near-infrared irradiation to achieve the required temperature. Thus, the precise control of the required temperature and the gradual attenuation of light intensity for tissue penetration remains challenging. Failure to control temperature and light intensity often lead to tissue perforation with local overheating, and failure in thermal ablation of large-volume tumors; therefore, the type I near-infrared photosensitizer-mediated photothermal therapy including IR780 has potential mainly in the treatment of superficial solid tumors [42, 43]. Lowdose photodynamic therapy (PDT) has been reported to induce the generation of endogenous reactive oxygen species (ROS) in the electron transport chain of mitochondria, and additional ROS promoted apoptosis [44]. Due to the ability of IR780 to target mitochondria, PDT can be achieved at a lower dose than that used for regular photothermal therapy [45]. Therefore, we focused on IR780-mediated PDT in combination with PTX treatment, with the eventual aim of improving antitumor therapy and reducing side effects.

The anti-tumor effects of functionalized nanoparticles are usually related to their long-term circulation, targeting, controlled release and other behaviors in vivo. However, the in vivo microenvironment is difficult to be simulated in an in vitro cell culture model. Therefore, we only investigated the effect of HA\&RBCm-LCNPs-mediated photochemotherapy on A549 cells cultured in vitro, but did not compare the actions of different nanocarriers. Blank HA\&RBCm-LCNPs had little effect on cell viability (Additional file 1: Figure S4). The cytotoxicity of each preparation increased in a concentration-dependent manner within the ranges of $0.05-20 \mu \mathrm{g} / \mathrm{mL}$ paclitaxel and $0.01-4 \mu \mathrm{g} / \mathrm{mL}$ IR780. The NIR-treated PTX/IR780loaded groups achieved higher levels of cytotoxicity than the groups without NIR $(p<0.01)$, indicating that the combination of chemotherapy and phototherapy using PTX and IR780 was better than chemotherapy using PTX alone. Within the NIR-treated groups, the $\mathrm{IC}_{50}$ in the HA\&RBCm-LCNP group was lower than that in the RBCm-LCNP group (Additional file 1: Table S2), owing to the receptor (CD44) and ligand (HA) interaction that significantly increased nanoparticle uptake by A549 cells $[46,47]$. In addition, the $\mathrm{IC}_{50}$ value in the NIR-treated PTX-HA\&RBCm-LCNP group was slightly lower than that in the non-NIR-treated PTX/IR780-HA\&RBCmLCNP group (1.84 vs. 2.00), owing to the low dark toxicity of IR780 in the concentration range examined.

Photochemotherapy conspicuously increased apoptosis compared with chemotherapy (Fig. 5A), which was confirmed via flow cytometry. The rate of A549 apoptosis was higher in the NIR-treated PTX/IR780-HA\&RBCmLCNP group than in the control and non-NIR-treated PTX/IR780-HA\&RBCm-LCNP groups $\quad(p<0.0001$; Fig. 5B, C).

Previous reports have shown that the enhanced outcomes of combinational treatment with PTX and IR780 were associated with the promotion of tumor cell apoptosis via a prolonged G2 phase of the cell cycle and ROS-mediated PDT, which were in agreement with our findings [38, 39]. Following exposure to NIR, PTX/ IR780-HA\&RBCm-LCNPs successfully induced A549 cells to produce a large amount of ROS, whereas without NIR irradiation, no obvious ROS production was observed (Fig. 5D). Tubulin is the target through which PTX inhibits tumor cell proliferation. PTX binds tubulin to prevent the compression of $\alpha$ - and $\beta$-tubulin, resulting in no tension accumulation and depolymerization [48]. The microtubules in the cells in the control group were morphologically regular, densely distributed in the cytoplasm, clearly filamentous, and formed a fusiform network-like structure around the nuclei (Fig. 5E). The cell morphology in the non-NIR-treated PTX/IR780HA\&RBCm-LCNP group did not change conspicuously but the number of cells was reduced, microtubules gathered around the nuclei, and the microtubules were irregularly shape with unclear structure, which resulted in a loss of cellular polarity. In the NIR-treated PTX/IR780HA\&RBCm-LCNP group, the cells shrunk significantly and were further reduced in number, with a diminution in microtubules and an obvious change in morphology, indicating that photochemotherapy inhibited cell proliferation and the production and depolymerization of microtubules. 

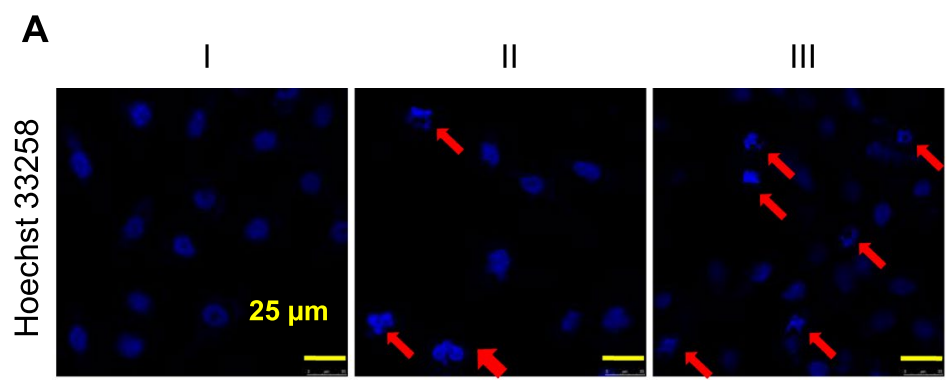

C

B
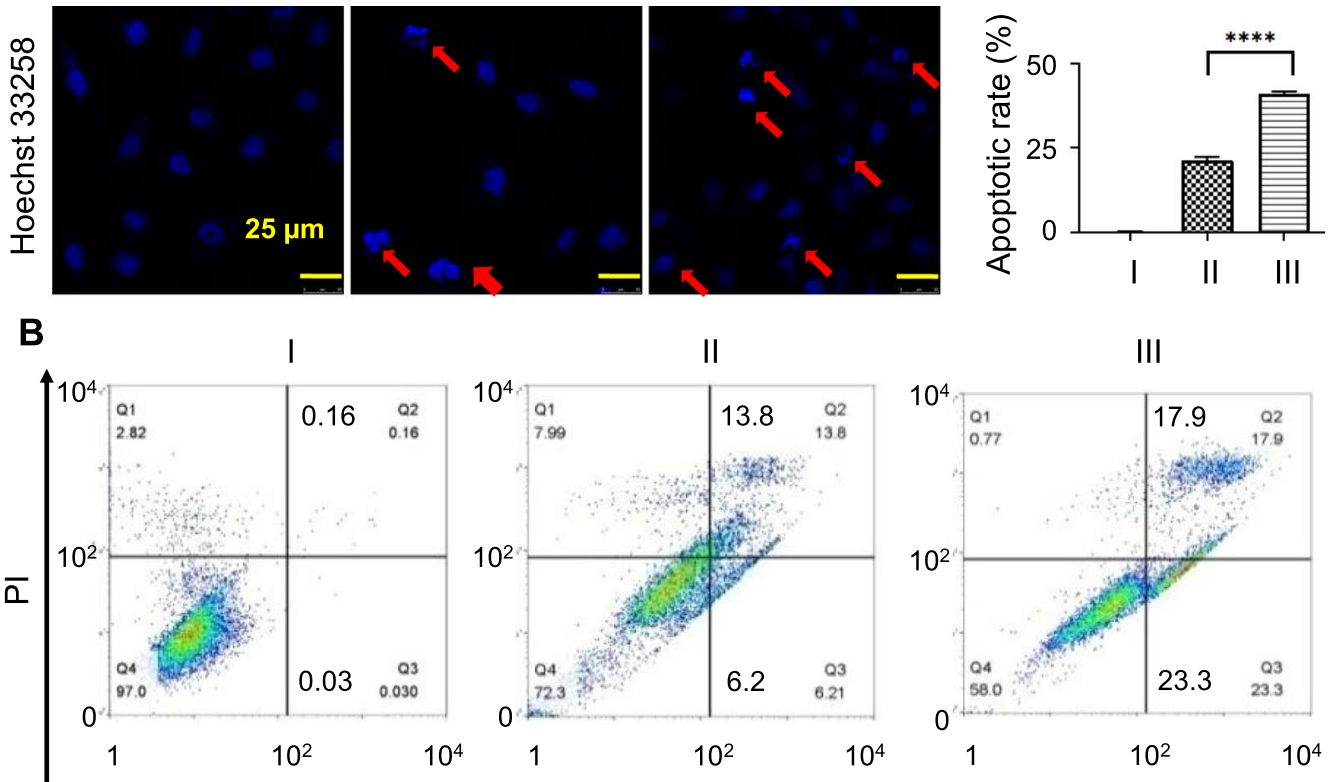

Annexin V-FITC
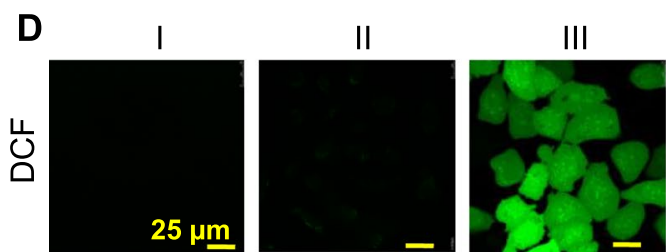

E

E
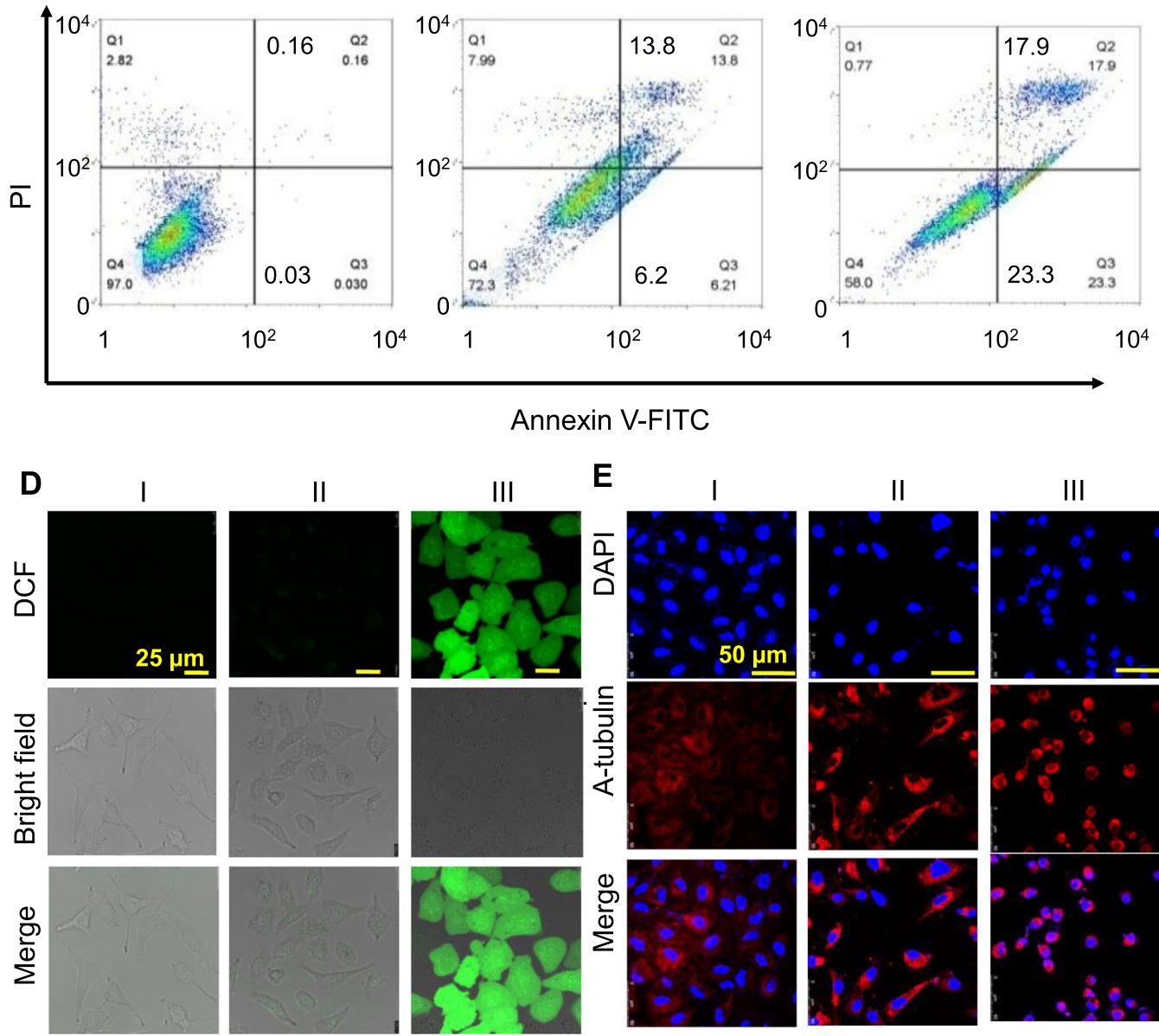

III

I, Control; II, PTX/IR780-HA\&RBCm-LCNPs; III, PTX/IR780-HA\&RBCm-LCNPs+NIR

Fig. 5 Apoptosis of A549 cells in vitro following treatment with PTX and IR780 co-loaded preparations. The "Control" (I), "PTX/ IR780-HA\&RBCm-LCNPs" (II), and "PTX/IR780-HA\&RBCm-LCNPs + NIR" (III) groups refer to cells not treated with drugs, non-NIR treated nano-formulations, and NIR-treated nano-formulations, respectively. A, D, E show confocal laser scanning microscope images of cells with Hoechst 33,258-labeled nuclei, 2',7'-Dichlorodihydrofluorescein diacetate (DCFH-DA)-labeled reactive oxygen species, and microtubules, respectively. B, C, Apoptosis measured via flow cytometry. For the phototherapy group, cells were exposed to NIR at $808 \mathrm{~nm}\left(1 \mathrm{~W} / \mathrm{cm}^{2}\right)$ for 5 min $2 \mathrm{~h}$ post-drug administration. The final PTX and IR780 concentrations were $5 \mu \mathrm{g} / \mathrm{mL}$ and $1 \mu \mathrm{g} / \mathrm{mL}$, respectively $(\mathrm{n}=3) .{ }^{* * * *} p<0.0001$

We further found that the NIR-treated PTX/IR780HA\&RBCm-LCNPs promoted apoptosis not only by destroying the microtubules but also by stimulating apoptosis-related proteins, such as the PDT-induced endogenous mitochondrial apoptotic pathway resulting from the preferential accumulation of IR780 in the mitochondria of tumor cells, which was associated with B-cell lymphoma 2 (Bcl-2) and $\mathrm{Bcl}-2$-associated $\mathrm{X}$ protein 

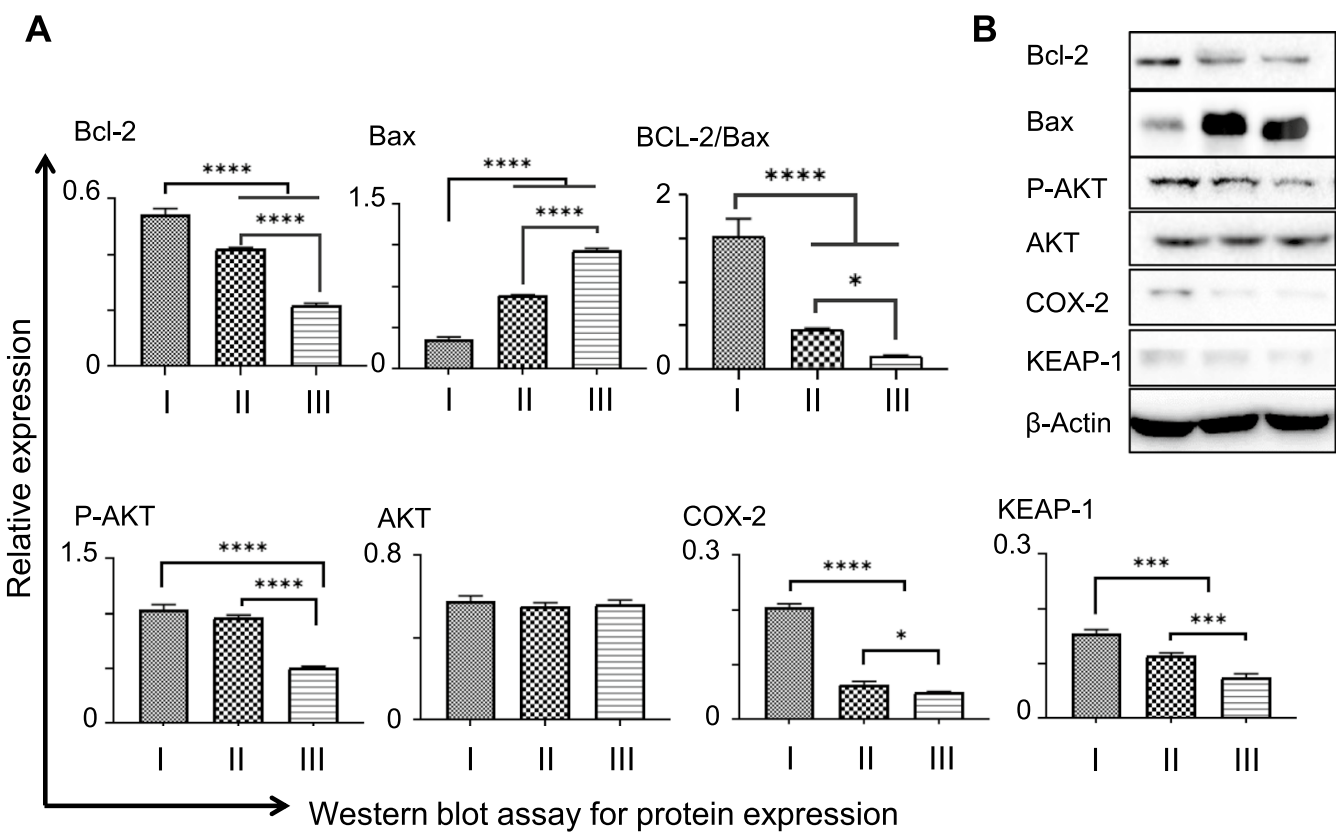

KEAP-1

0.3

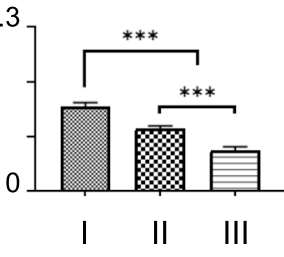

I, Control; II, PTX/IR780-HA\&RBCm-LCNPs; III, PTX/IR780-HA\&RBCm-LCNPs+NIR

Fig. 6 Changes in the expression of apoptosis-associated proteins in A549 cells treated with PTX and IR780 co-loaded preparations. The "Control" (I), "PTX/IR780-HA\&RBCm-LCNPs" (II), and "PTX/IR780-HA\&RBCm-LCNPs + NIR" (III) groups refer to cells not treated with drugs, non-NIR treated nano-formulations, and NIR-treated nano-formulations, respectively. A the apoptosis-related proteins assayed through western blotting $(n=3)$; B western blotting bands. For the phototherapy group, cells were exposed to NIR at $808 \mathrm{~nm}\left(1 \mathrm{~W} / \mathrm{cm}^{2}\right)$ for $5 \mathrm{~min} 2 \mathrm{~h}$ post-drug administration. BCl-2 B-cell lymphoma 2, Bax Bcl-2-associated X protein, COX-2 cyclooxygenase-2. ${ }^{* * *} p<0.0001,{ }^{* * *} p<0.001,{ }^{*} p<0.05$

(Bax) (Fig. 6A, B) [45, 49]. Bcl-2 is an anti-apoptotic protein that maintains the mitochondrial membrane potential and blocks the release of cytochrome $C$ [50]. Bax is a pro-apoptotic protein that eliminates the mitochondrial membrane potential to promote the release of cytochrome $C$, thereby activating the enzyme caspase cascade, and ultimately leading to apoptosis. Bcl-2 and Bax in the cells in the drug-treatment groups were downand upregulated, respectively $(p<0.0001)$, relative to the control group. The ratios of $\mathrm{Bcl}-2$ to $\mathrm{Bax}(\mathrm{Bcl}-2 / \mathrm{Bax})$ in the drug-treatment groups were remarkably decreased relative to the control group $(p<0.0001)$, indicating that PTX/IR780-HA\&RBCm-LCNP induced apoptosis through the endogenous mitochondrial pathway. Notably, the NIR-treated group showed stronger regulatory effects on Bcl-2 and Bax than the non-NIR-treated PTX/ IR780-HA\&RBCm-LCNP group $(p<0.0001)$, as shown by a lower $\mathrm{Bcl}-2 / \mathrm{Bax}$ ratio $(p<0.05)$, suggesting that ROS-induced apoptosis was involved.

Serine/threonine kinase Akt, another proto-oncogene involved in the intracellular conduction pathway, is activated by phosphatidylinositol 3-kinase (PI3K) to generate phosphorylated-Akt (p-Akt), inhibit apoptosis, and promote cell cycle progression [51]. In our study, the PTX/IR780-HA\&RBCm-LCNPs with or without NIR-treatment had no noticeable effects on the total Akt expression levels in A549 cells $(p>0.05)$. However, NIR treatment of PDT inhibited the activation of the PI3K/Akt pathway by downregulating p-Akt, relative to the control and non-NIR-treated PTX/ IR780-HA\&RBCm-LCNP groups $(p<0.0001)$, thereby sensitizing cells to ROS-mediated apoptosis [52, 53]. Furthermore, Kelch-like ECH-associated protein 1 (Keap1), the main inhibitor of the nuclear factor erythroid 2-related factor 2 (Nrf2), was also significantly inhibited in A549 cells in the treated groups relative to the control group $(p<0.001)$, and the expression levels of Keap1 in the NIR-treated group was lower than that in the non-NIR-treated group $(p<0.001)$. Keap1/Nrf2 is an important pathway for anti-oxidative responses in cells [54]. PDT produces excess ROS and downregulates Keap1, thereby triggering apoptosis; the PI3K/Akt pathway initiates the production of ROS by weakening Nrf2 stability, which contributes to sensitization and the reversion of resistance to chemotherapeutic drugs such as PTX $[55,56]$. Therefore, we speculated that the effects of NIR-treated PTX/IR780-HA\&RBCm-LCNPs on p-Akt and Keap1 has the potential to reverse the 
resistance of A549 cells to PTX. We also found that PTX/IR780-HA\&RBCm-LCNPs substantially lowered the expression of intracellular cyclooxygenase-2 (COX2) $(p<0.0001)$, and NIR irradiation probably enhanced this downregulation $(p<0.05)$. COX-2 expression has been reported to upregulate $\mathrm{Bcl}-2$ in rat intestinal epithelial cells, repress the cleavage of caspase- 3 in oral squamous cell carcinoma, and is accompanied by the increased phosphorylation of Akt in endometrial cancer cells, thereby inhibiting tumor cell apoptosis and promoting tumor growth [57-59]. It also upregulates membrane-type matrix metalloproteinases (MMPs), such as MMP-2, in human colon cancer cells to promote tumor cell infiltration and metastasis [60]. Therefore, the inhibition of COX-2 can reverse the inhibition of tumor cell apoptosis and migration. However, a previous report has shown that hypericin-mediated PDT increases the amount of COX-2 in HeLa cells and a T24 (human transitional cell carcinoma of the urinary bladder) cell culture [61]. It can be inferred that the regulatory effects of PTX/IR780-HA\&RBCm-LCNPs on COX-2 in A549 cells is related to the inhibition of COX-2 expression by PTX and IR780 [62].

The ability to PTX/IR780-HA\&RBCm-LCNPs to disrupt microtubules and to regulate migration-associated signals, including the aforementioned protein pathways, lead to the reduced migratory capacity of A549 cells [60, 63]. Because the drug concentration that was effective in the apoptosis experiment had too much inhibitory effects on cell migration, the effects of the different treatment groups on migration were difficult to assess. Thus, we reduced the concentrations of PTX and IR780 to $2.5 \mu \mathrm{g} /$ $\mathrm{mL}$ and $0.5 \mu \mathrm{g} / \mathrm{mL}$, respectively. Micrographs of the changes in scratches at 0 and $24 \mathrm{~h}$ are shown in Fig. 7A. At $24 \mathrm{~h}$, the cell migration rate was $91.81 \%$ in the control group, and almost all scratches had healed. However, the cell migration rate in each nano-formulation-treated group was significantly less than that in the control group (Fig. $7 \mathrm{~B} ; p<0.0001$ ). Moreover, the migration rate in the NIR-treated PTX/IR780-HA\&RBCm-LCNP

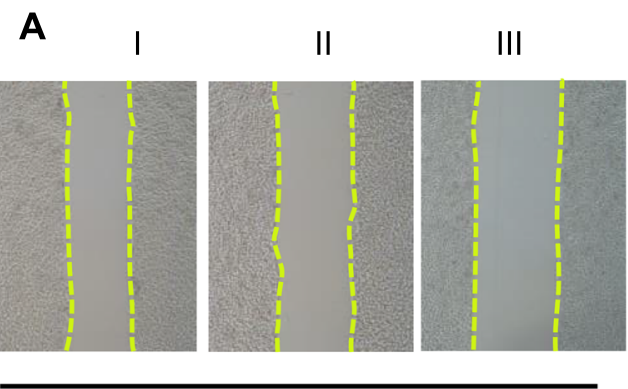

$\mathrm{Oh}$

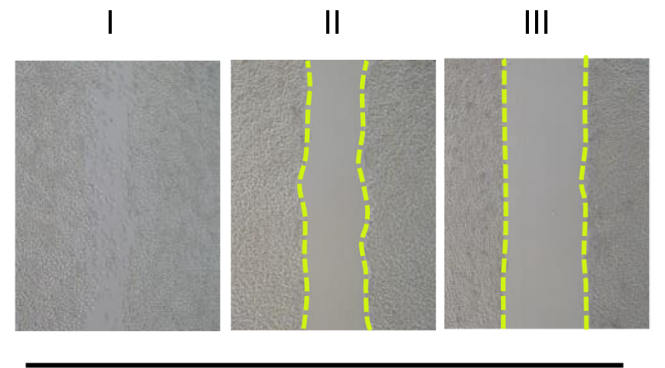

$24 \mathrm{~h}$
B

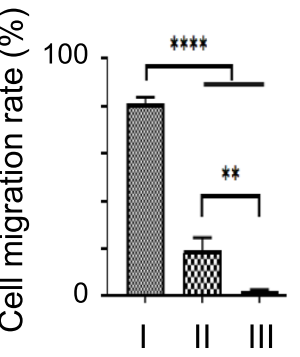

C

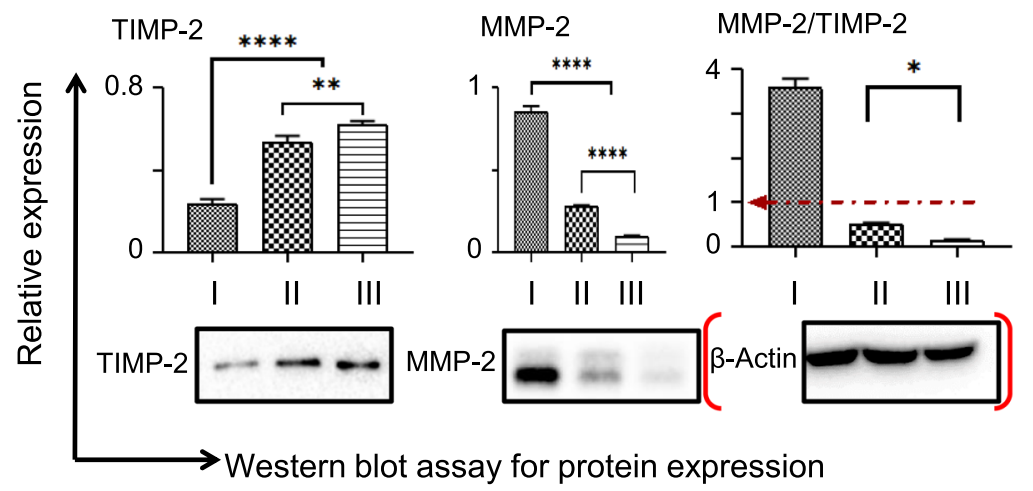

I, Control; II, PTX/IR780-HA\&RBCm-LCNPs; III, PTX/IR780-HA\&RBCm-LCNPs+NIR

Fig. 7 Migration of A549 cells in vitro following treatment with PTX and IR780 co-loaded preparations. The "Control" (I), "PTX/ IR780-HA\&RBCm-LCNPs" (II), and "PTX/IR780-HA\&RBCm-LCNPS + NIR" (III) refer to cells not treated with drugs, non-NIR treated nano-formulations, and NIR-treated nano-formulations, respectively. A Cell migration micrographs; $\mathbf{B}$ cell migration rates; $\mathbf{C}$ related proteins assayed by western blotting. The final PTX and IR780 concentrations were $2.5 \mu \mathrm{g} / \mathrm{mL}$ and $0.5 \mu \mathrm{g} / \mathrm{mL}$, respectively $(\mathrm{n}=3$ ). For the phototherapy group, cells were exposed to NIR at $808 \mathrm{~nm}\left(1 \mathrm{~W} / \mathrm{cm}^{2}\right)$ for $5 \mathrm{~min} 2 \mathrm{~h}$ post-drug administration. MMP-2 matrix metalloproteinase 2; tissue inhibitor 2 of matrix metalloproteinase-2, TIMP-2. ${ }^{* * *} p<0.0001,{ }^{* *} p<0.01,{ }^{*} p<0.05$ 
group was significantly lower than that in the non-NIRtreated group $(p<0.01)$. The results corresponded with the expression levels of MMP-2 and tissue inhibitor 2 of matrix metalloproteinase-2 (TIMP-2) in the tested groups (Fig. 7C). High expression levels of MMP-2 is closely related to infiltration and vascular invasion of the basement membrane and the interstitium as well as to the metastasis of tumor cells. However, MMP-2 is inhibited by TIMP-2 [60]. In our study, the expression of these two proteins were dramatically inhibited in A549 cells in the treated groups $(p<0.0001)$; the NIR-treated PTX/IR780HA\&RBCm-LCNPs downregulated MMP-2 $(p<0.0001)$ and TIMP-2 $(p<0.01)$, and the MMP-2/TIMP-2 ratio (less than 1 in both administration groups) was lower than that in the group without NIR irradiation $(p<0.05)$, suggesting that NIR-treated PTX/IR780-HA\&RBCmLCNPs induced A549 apoptosis and inhibited migration via microtubule-, ROS-, and mitochondrial stress-related pathways. The inhibition of migration also likely involved the MMP-2/TIMP-2 signaling pathway and COX-2 regulation.

\section{Circulation and tumor targeting capacity in vivo}

Our in vitro uptake experiments showed that HA\&RBCm-LCNPs effectively decreased macrophage phagocytosis, which may lead to extended circulation in the blood. This was confirmed by the subsequent in vivo pharmacokinetic studies in rats (Fig. 8A). Following intravenous administration of the formulations, the plasma concentrations of PTX in the PTX/IR780solution group and the PTX/IR780-LCNP group were less than the detection limit at 8 and $24 \mathrm{~h}$, respectively. In contrast, the PTX/IR780-RBCm-LCNPs and PTX/ IR780-HA\&RBCm-LCNPs were detectable up to $72 \mathrm{~h}$ post-administration (Additional file 1: Figure S5). The half-life $\left(\mathrm{T}_{1 / 2}\right)$, area under the curve $\left(\mathrm{AUC}_{0-\mathrm{t}}\right)$, and peak concentration $\left(\mathrm{C}_{\max }\right)$ in the PTX/IR780-RBCm-LCNP group were 9.56- and 3.14-fold, 5.91- and 3.97-fold higher than in the PTX/IR780-solution group, respectively, and were 3.08- and 3.26-fold higher than in the PTX/IR780LCNP group, respectively. The mean residence time $\left(\mathrm{MRT}_{0-t}\right)$ in the PTX/IR780-solution group was only $0.5 \pm 0.25 \mathrm{~h}$, whereas those in the PTX/IR780-LCNP and
PTX/IR780-RBCm-LCNP groups were 5.8- and 15.24fold higher, respectively. The clearance rate in the PTX/ IR780-RBCm-LCNP group was also significantly lower than those in the PTX/IR780-solution and PTX/IR780LCNP groups.

The RBCm-camouflaged LCNPs could successfully escape from phagocytosis by macrophages, effectively prolonging the $t_{1 / 2}$ and $\mathrm{MRT}_{0-\mathrm{t}}$ of PTX, and marginally improving drug bioavailability [64]. A previous study has shown that $\mathrm{RBCm}$-coated nanoparticles have a $t_{1 / 2}$ of $39.6 \mathrm{~h}$, which is more than twice the $\mathrm{t}_{1 / 2}$ of PEGylated nanoparticles (15.8 h) [65]. Chao et al. reported that, compared with non-PEGylated liposomes, PEGylated liposomes adsorbed less proteins in the blood, which mainly reduced the affinity of immunoglobulins. However, apolipoprotein E, which has been shown to retard the phagocytosis of macrophages, was not found in the protein corona of PEGylated liposomes [66]. In our work, the protein compositions in the $\mathrm{RBCm}$ and the bloodtreated nanocarriers (LCNPs and HA\&RBCm-LCNPs) were quite different (Fig. 8B, C). The amounts of fibrinogen gamma chain $(50.632 \mathrm{kDa})$, an important protein in the protein crown, in the LCNP and HA\&RBCm-LCNP groups were not statistically different $(p>0.05)$ (Additional file 2) [67]. Immunoglobulins and complement proteins are generally considered to induce opsonization and RES recognition $[68,69]$. The amounts of immunoglobulins (Igs), such as Ig gamma-2 A chain $\mathrm{C}$ region $(35.18 \mathrm{kDa})$, Ig gamma-2B chain $\mathrm{C}$ region $(36.49 \mathrm{kDa})$, and Ig gamma-2 chain $\mathrm{C}$ region $(11.37 \mathrm{kDa})$ in the protein crowns of LCNPs and HA\&RBCm-LCNPs were also not statistically different $(p>0.05)$. By contrast, certain complement proteins, such as C3 $(186.32 \mathrm{kDa}), \mathrm{C} 4$ (192.16 kDa), C5 (189.08 kDa), C9 (62.28 kDa), C1q subcomponent subunits-A (25.917 kDa), -B (26.647 kDa) and -C $(25.686 \mathrm{kDa})$, which may not shorten the circulation time of nanocarriers, were higher in the HA\&RBCmLCNP group than in the LCNP group (Fig. 8D; Additional file 2). However, the amount of leukocyte surface antigen CD47 $(32.995 \mathrm{kDa})$ in the HA\&RBCm-LCNP group contained was significantly higher than that in the LCNP group $(p<0.05)$. Meanwhile, the amounts of certain myosins, including tropomyosin alpha-3 chain $(29.006 \mathrm{kDa})$, tropomyosin alpha-4 chain $(28.509 \mathrm{kDa})$,

\footnotetext{
(See figure on next page.)

Fig. 8 Circulation of nanoparticles in vivo. A In vivo pharmacokinetic properties of PTX, and the biodistribution of PTX and IR780 following intravenous administration of PTX and IR780 co-loaded preparations in rats. The doses of PTX and IR780 were $5 \mathrm{mg} / \mathrm{kg}$ and $1 \mathrm{mg} / \mathrm{kg}$, respectively $(n=6)$. B Results of crown protein analysis via sodium dodecyl sulfate-polyacrylamide gel electrophoresis. C Bubble map of the top 15 entries from a Gene Ontology (GO) enrichment analysis. The GO entries were screened for differential proteins with scores greater than 1 in the three categories. Then, the top 5 corresponding $-\log _{10} p$-values were obtained from each entry. Entries with larger bubbles indicate more proteins. Color change from yellow to red suggests that the enrichment $p$-value is smaller and the significant difference is greater. NS, not significant; $p>0.05 ;{ }^{*} p<0.05$, ${ }^{* *} p<0.01$
} 


\section{A}

I, PTX/IR780 -solution

II, PTX/IR780-LCNPs

III, PTX/IR780-RBCm-LCNPs

IV, PTX/IR780-HA\&RBCm-LCNPs
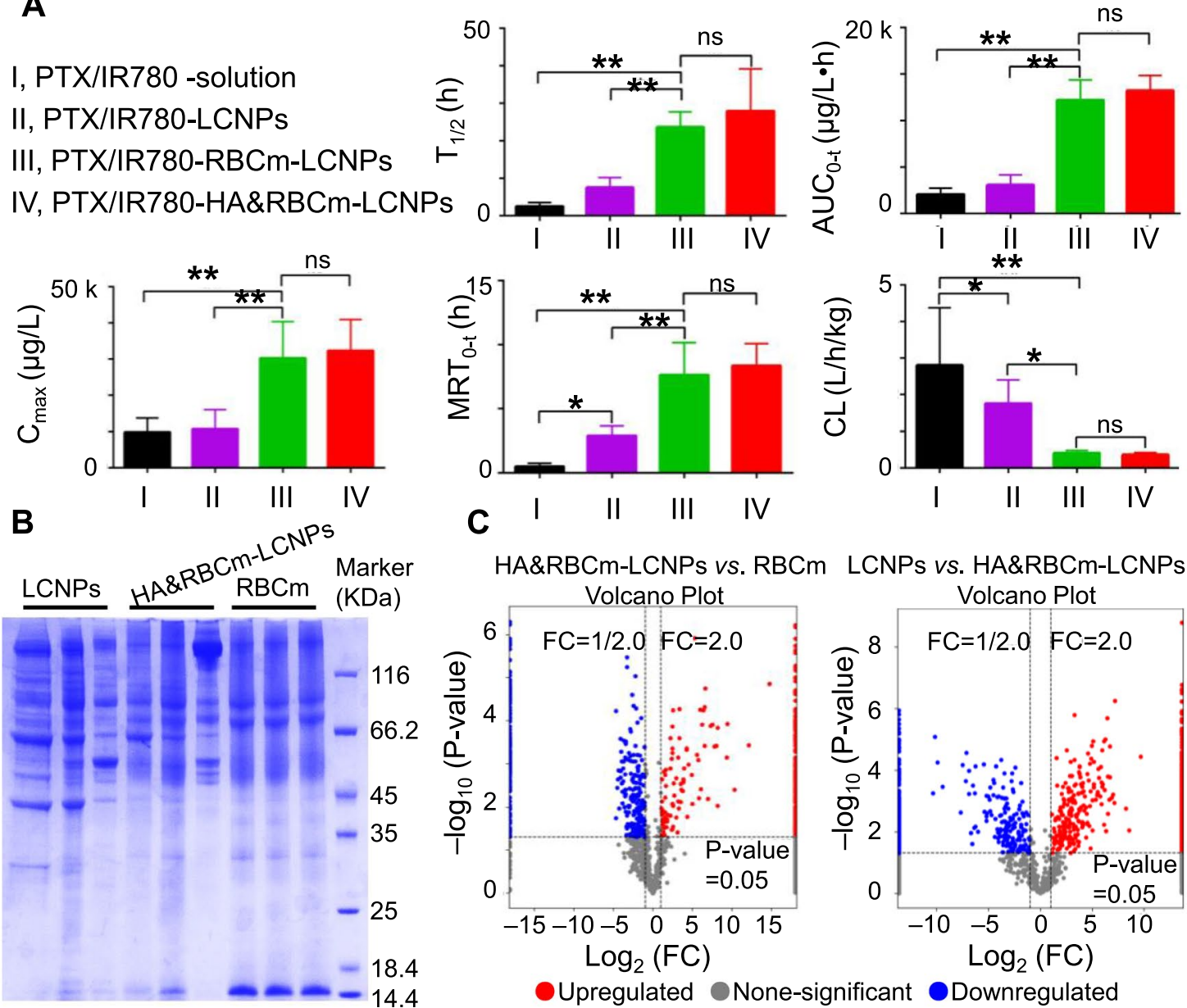

HA\&RBCm-LCNPs vs. RBCm LCNPs vs. HA\&RBCm-LCNPs
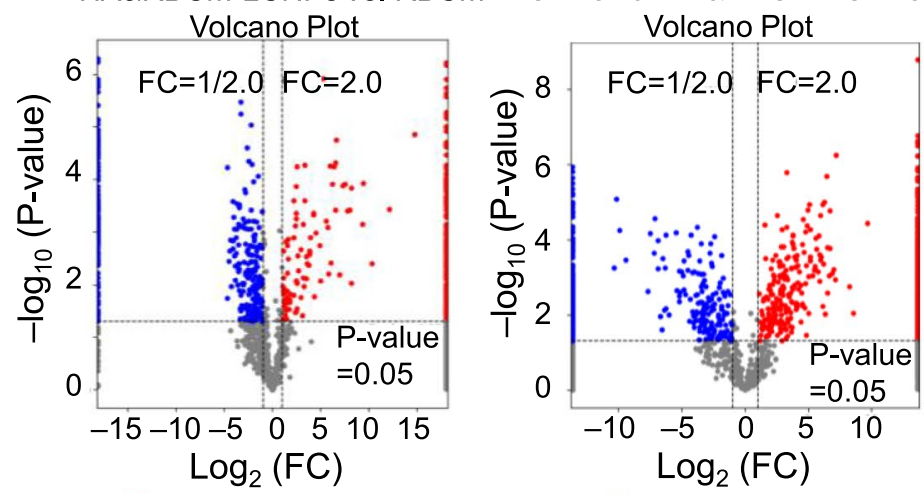

D

LCNPs vs. HA\&RBCm-LCNPs

LCNPs vs. HA\&RBCm-LCNPs

(Down)

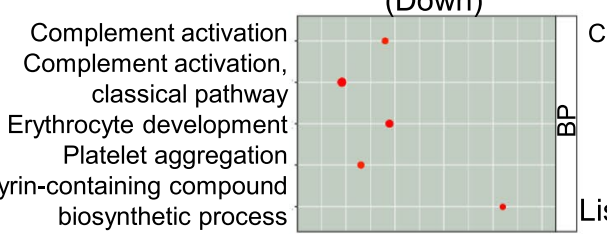

Cellular response to interleukin-7

ListHits

COPII-coated ER to Golgi

transport vesicle

Cortical cytoskeleton

Endoplasmic reticulum

Melanosom

Membrane

GDP binding

GTP binding

GTPase activity

Integrin binding

NADH dehydrogenase activity

1020304050

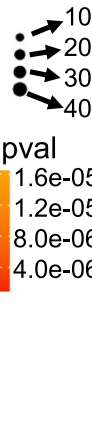

$1.6 \mathrm{e}-05$

$1.2 \mathrm{e}-05$

.0e-06

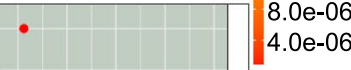

Enrichment-score Intracellular protein transport Positive regulation of cell

adhesion
Positive regulation of $\mathrm{T}$ cell

mediated cytotoxicity

(Up)

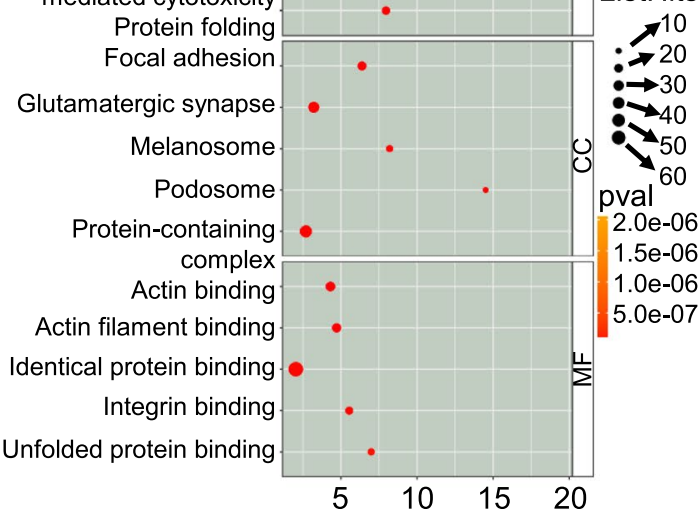

Enrichment-score

Fig. 8 (See legend on previous page.) 
and filamin A (280.49 kDa), that adhered to the LCNPs were markedly higher than those that adhered to the HA\&RBCm-LCNPs $(p<0.05)$. CD47 protein is recognized as a "Don't eat me" signal protein, and myosin, such as myosin VII, has been reported to be positively related to phagocytosis by macrophages [70]. In conclusion, the prolonged circulation of HA\&RBCm-LCNPs in the blood is considered to have been achieved via the following: (1) alterations to the types rather than the amounts of proteins attached to the surface of the nanoparticles; (2) an abundance of CD47 and reduced affinity to myosins; and (3) excellent sustained-release properties. In addition, apolipoprotein $\mathrm{E}$ was detected in both LCNP and HA\&RBCm-LCNP groups $(p>0.05)$, suggesting that the circulatory properties of the tested nanocarriers are distinct from those of PEGylated nanoparticles [66].

The pharmacokinetic parameters in the PTX/IR780HA\&RBCm-LCNP group did not statistically differ from those in the PTX/IR780-RBCm-LCNP group, indicating that HA modification had no apparent effects on the circulation of PTX/IR780-RBCm-LCNPs. However, although not statistically different, the circulation of HA\&RBCm-LCNPs was superior to those of RBCmLCNPs as suggested by the parameters, which partly echoes the results of the macrophage phagocytosis studies in vitro and also demonstrates the more complex fate of nanocarriers in vivo.

HA\&RBCm-LCNPs possess multiple characteristics, including sustained release, long circulation in the blood, and active targeting, that contribute to increased accumulation in tumors. Six hours following administration, PTX accumulation in the tumor in the PTX/ IR780-HA\&RBCm-LCNP group was 4.33- and 4.23-fold higher than that in the PTX/IR780-LCNP group and the PTX/IR780-solution group, respectively, and was significantly higher than that in the PTX/IR780-RBCm-LCNP group $(p<0.05)$ (Fig. 9A). PTX accumulation was lowest in the heart of tumor-bearing nude mice. However,

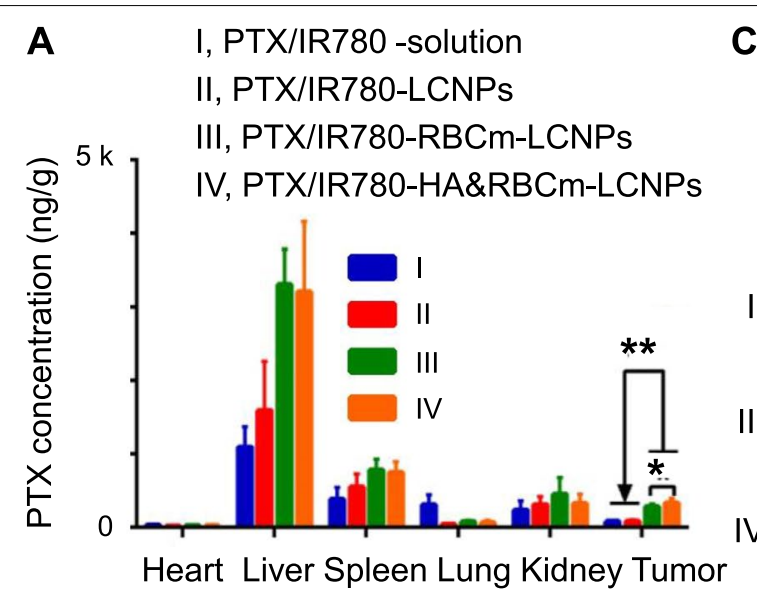

C

B
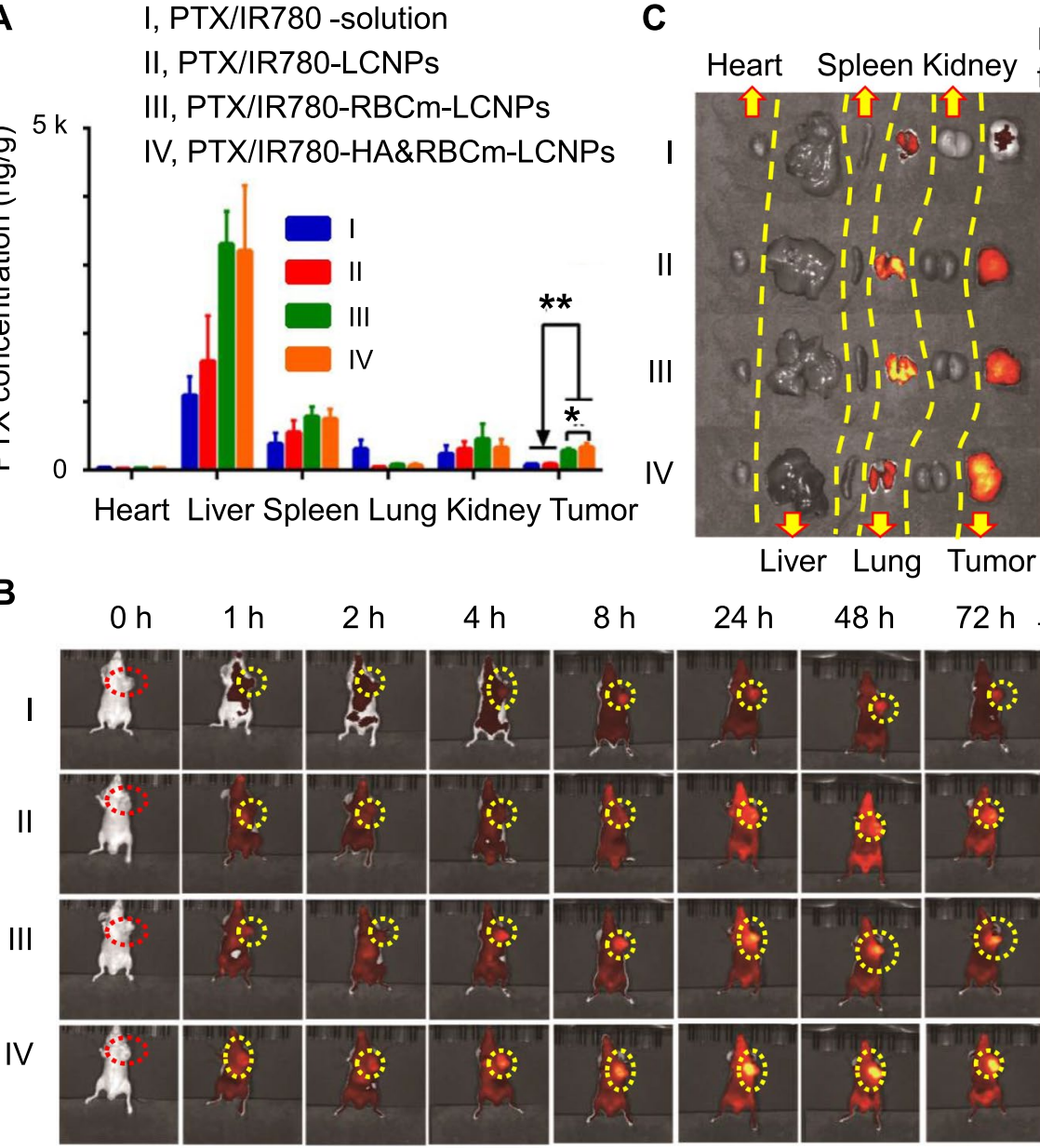

Epi-

fluorescence

Liver Lung Tumor

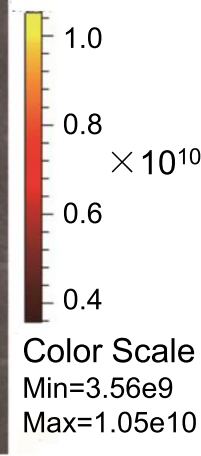

Min=3.56e9

$\operatorname{Max}=1.05 \mathrm{e} 10$

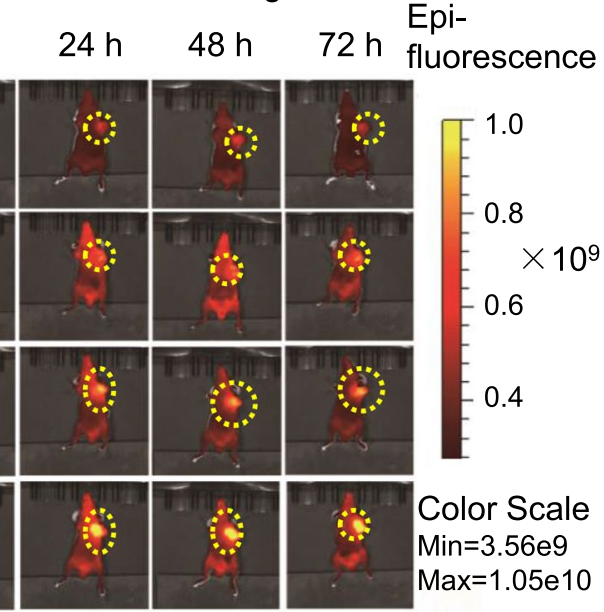

Fig. 9 In vivo biodistribution of A PTX and B, C IR780 in tumor-bearing nude mice following intravenous administration of PTX and IR780 co-loaded preparations for $6 \mathrm{~h}$ (PTX) and over $72 \mathrm{~h}$ (IR780). The doses of PTX and IR780 were $5 \mathrm{mg} / \mathrm{kg}$ and $1 \mathrm{mg} / \mathrm{kg}$, respectively ( $\mathrm{n}=6$ ). NS, not significant; $p>0.05 ;{ }^{*} p<0.05,{ }^{* *} p<0.01$ 
PTX accumulation in the liver and spleen of mice in the $\mathrm{RBCm}$-coated group was higher than in mice in the LCNP group. This is probably due to the fact that, as reported, the rich blood stored in these two isolated tissues was not removed through perfusion before sample preparation, and the nanoparticles in the blood contributed a large amount of drugs, further demonstrating the excellent circulation profile of the $\mathrm{RBCm}$-coated nanocarriers [71].

The dynamic tissue distribution of nano-formulations in tumor-bearing nude mice was visually monitored using small animal imaging systems. IR780 has the property of targeting the mitochondria and allows long-term imaging in vivo. Previous reports have shown that mice had strong in vivo fluorescence signals until $48 \mathrm{~h}$ after intravenous administration of free IR780; Yang et al. and Zhang et al. demonstrated that at $48 \mathrm{~h}$ after administration of IR780-loaded nanoparticles, the fluorescence intensity at the tumor site was not significantly different or stronger than that at $12 \mathrm{~h}$ after administration [72-74]. Here, we found that after $72 \mathrm{~h}$ of intravenous administration, the mice in each group still exhibited IR780 fluorescence, but the fluorescence intensity was remarkably reduced. Since the drug in the systemic circulation gradually decreased over time, the drug distribution in the isolated organs at $72 \mathrm{~h}$ had noticeable differences from those observed at $6 \mathrm{~h}$ after administration. The fluorescence of IR780 at the tumor site of the PTX/IR780-HA\&RBCm-LCNP group was the highest among the tested groups, and the fluorescence intensity increased with time (Fig. 9B). Fluorescence in the lungs and tumors of mice in the PTX/ IR780-LCNP and PTX/IR780-RBCm-LCNP groups were higher than those in the PTX/IR780-solution group. In the PTX/IR780-HA\&RBCm-LCNP group, the fluorescence intensity in the tumor was further increased, while that in the lung was reduced likely owing to the HAmediated tumor-targeting capacity of the nanocarriers.

\section{In vivo antitumor activity}

During the 13-day treatment period, the tumor volume increased in varying degrees in each group of tumorbearing nude micetumor-bearing nude mice. The most pronounced increase was observed in the normal saline group and the commercial PTX Injection (normal aqueous solution) group (Fig. 10A). During the experimental duration, the increase in tumor volume in the NIR-treated groups were slower than those in the nonNIR-treated groups $(p<0.05)$. In particular, tumor volume in the NIR-treated PTX/IR780-HA\&RBCm-LCNP group was maintained at $\sim 200 \mathrm{~mm}^{3}$ and was the smallest among all groups following treatment $(p<0.05)$. At the end of treatment, the drug administration groups achieved antitumor efficacy, with tumor weights lower than those in the saline control group $(p<0.05)$. Among the NIR-treated groups, the tumor weight in the PTX/IR780-HA\&RBCm-LCNP group was the lowest $(p<0.05)$. These results demonstrate that $\mathrm{RBCm}$ coating prolonged the circulation of nanoparticles and improved the antitumor effects of drug-loaded nanocarriers, and these effects were further enhanced by HA modification [75]. Furthermore, the antitumor effects of combined chemotherapy and PDT produced by PTX and low-dose IR780 was superior to the effects of chemotherapy alone, as the tumor weights in NIR-treated groups was lower than those in non-NIR-treated groups $(p<0.05)$.

The exposed $3^{\prime}-\mathrm{OH}$ in fragmented genomic DNA in apoptotic cells was labeled with fluorescein isothiocyanate (FITC) through the terminal deoxynucleotidyl transferase dUTP nick-end labeling (TUNEL) method, and tumor proliferation was evaluated through the detection of proliferating cell nuclear antigen (PCNA). The microscopy images (Fig. 10B) showed that the saline group had no obvious fluorescent markers in the tumor tissues, whereas the PTX Injection and non-NIR-treated PTX/IR780-HA\&RBCm-LCNP groups had only sporadic fluorescent markers, showing a few apoptotic cells. In contrast, there was dramatically more scattered TUNEL-stained green fluorescence in the NIR-treated groups $(p<0.0001)$. The number of fluorescent-positive cells was higher in the RBCm-coated groups than that in the uncoated nanoparticle group $(p<0.0001)$; the PTX/ IR780-HA\&RBCm-LCNP group had the greatest fluorescence distribution $(p<0.0001)$, indicating the highest number of apoptotic cells. The results of the PCNA analysis were similar to those of the TUNEL assay. PCNA-positive staining was primarily observed in the nuclei and was indicated by brown spots (Fig. 10C). The PCNA-positive to total cell ratio in tumor tissues in each treatment group was significantly lower than that in the saline group $(p<0.0001)$, and the ratios of PCNA-positive to total cell in the NIR-treated nano-preparation groups were lower than those in the non-NIR-treated groups $(p<0.0001)$. For the NIR-treated groups, the PTX/IR780$\mathrm{RBCm}$-LCNP group exhibited the lowest PCNA-positive to total cell ratio among the uncoated nano-preparation groups $(p<0.01)$, and the PCNA-positive to total cell ratio in the PTX/IR780-HA\&RBCm-LCNP group was the lowest among the tested groups $(p<0.0001)$. We further found that the induction of tumor cell apoptosis was associated with the $\mathrm{Bcl}-2 / \mathrm{Bax}$ and caspase-3 signaling pathways, and the NIR-treated PTX/IR780-HA\&RBCmLCNPs had the strongest upregulatory effects on caspase-3 in A549 tumor tissue $(p<0.0001)$. These results are in accordance with the results we obtained in the in vitro studies, indicating that PTX and IR780 induce the apoptosis of A549 cells via endogenous mitochondrial 
I, Saline; II, PTX Injection; III, PTX-HA\&RBCm-LCNPs;

IV, PTX/IR780-HA\&RBCm-LCNPs; V, PTX/IR780-LCNPs+NIR;

VI, PTX/IR780-RBCm-LCNPs+NIR; VII, PTX/IR780-HA\&RBCm-LCNPs+NIR

A

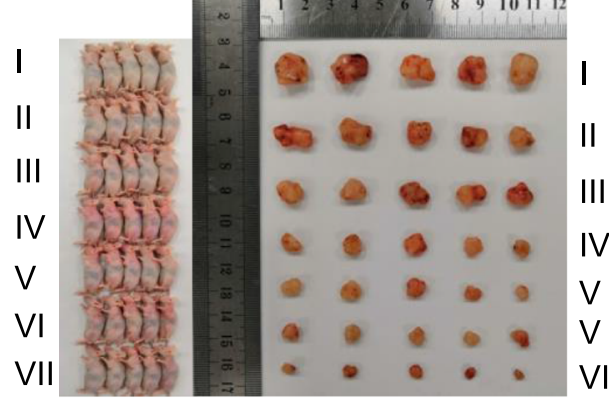

B

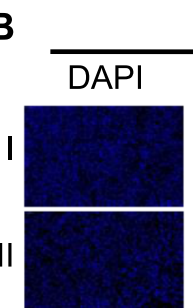

III

TUNEL
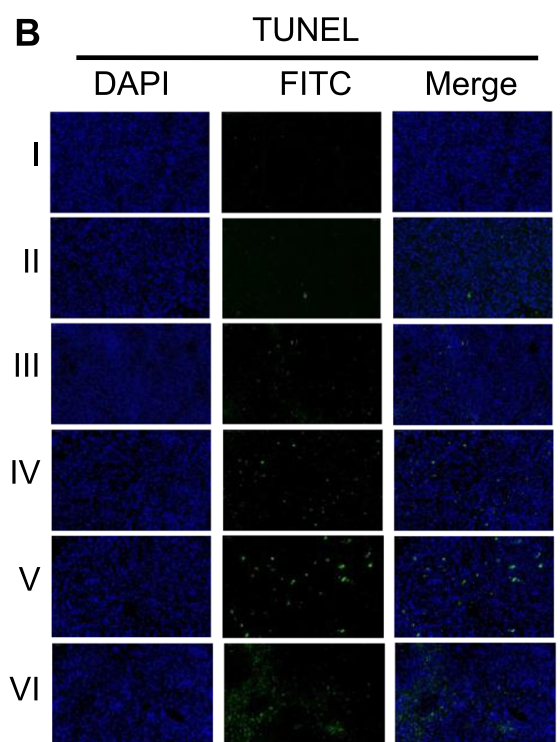

$\frac{\text { PCNA }}{\mathrm{IHC}}$
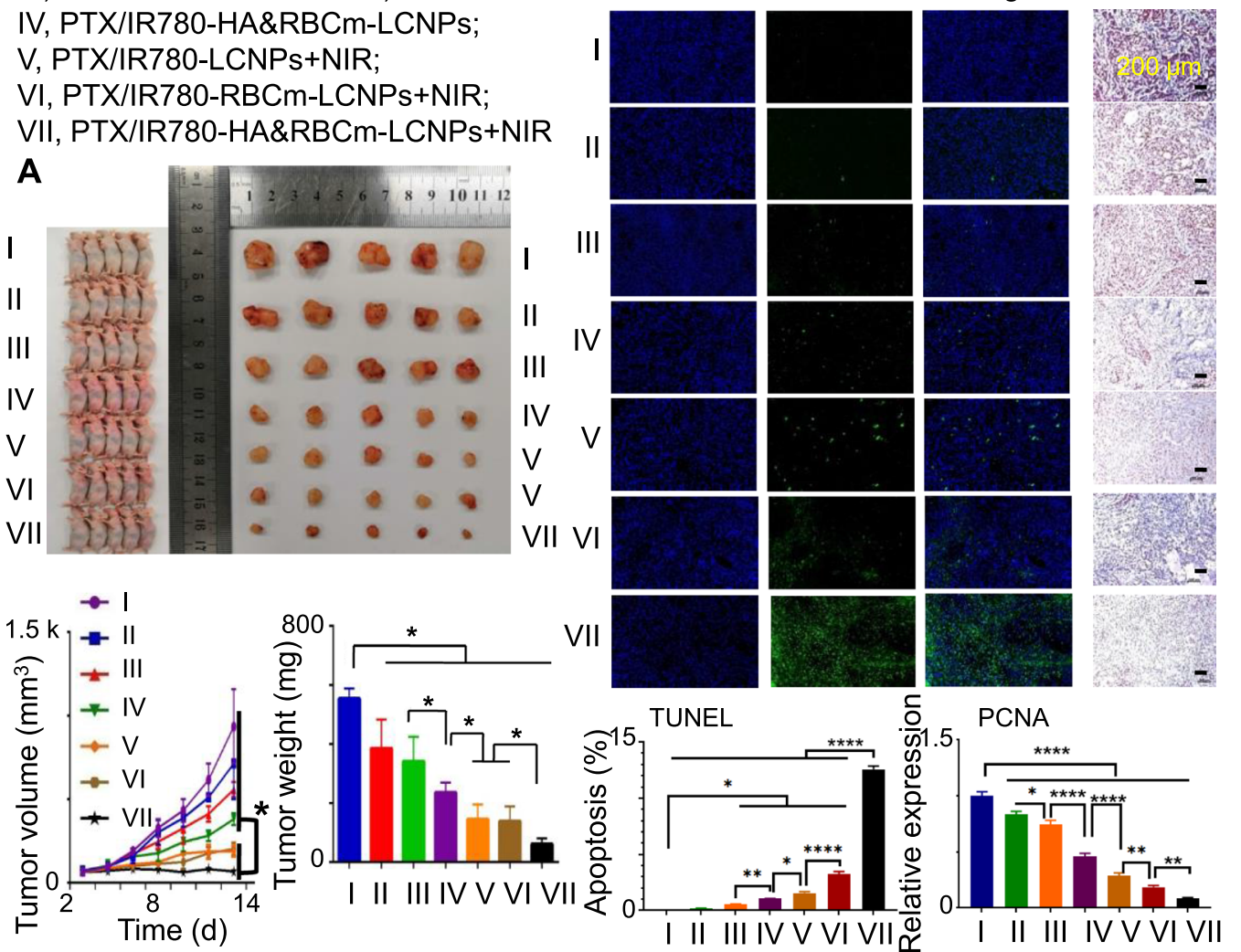

C
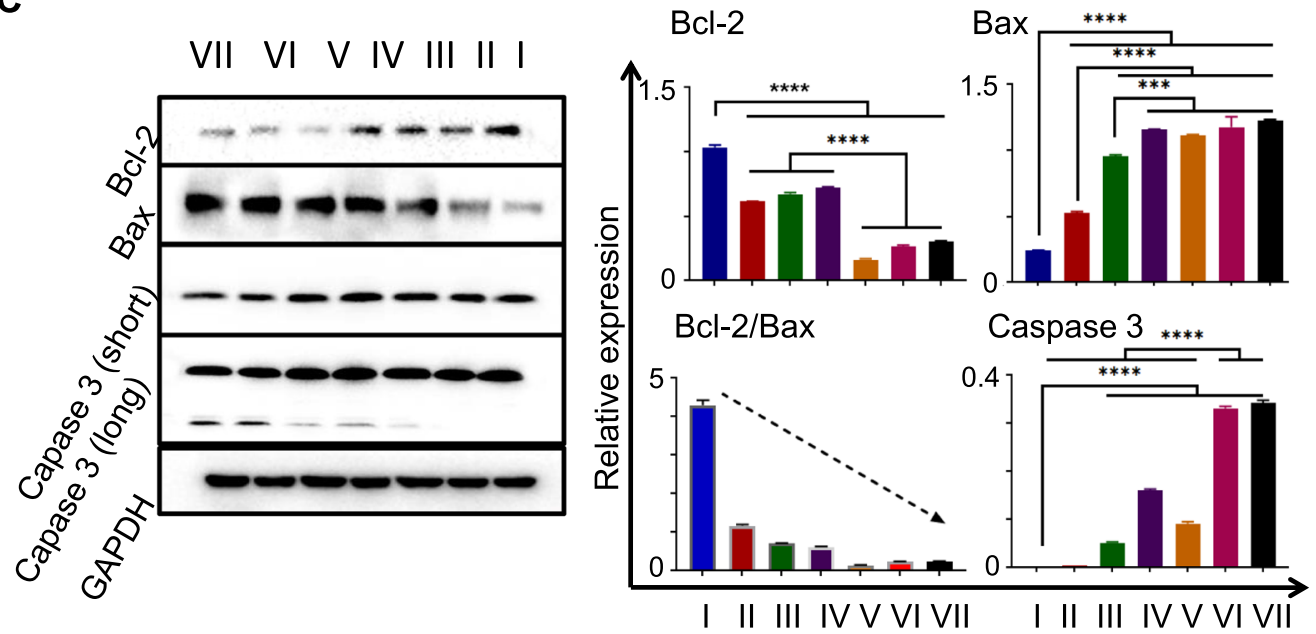

Fig. 10 In vivo antitumor effects of normal saline and drug-loaded preparations intravenously administered to tumor-bearing BALB/c nude mice once every 2 days for 12 days. Doses: PTX, 5 mg/kg; IR780, 1 mg/kg. Normal saline: Saline, control. A Images of tumors, tumor volume changes, and tumor weights at the end of the 13-day treatment period. B Micrographs of tumor tissue slices for proliferating cell nuclear antigen (PCNA) and terminal deoxynucleotidyl transferase dUTP nick-end labeling (TUNEL) analysis. CWestern blotting for apoptosis-related proteins $(n=5)$. For the phototherapy group, animals were exposed to NIR at $808 \mathrm{~nm}\left(1 \mathrm{~W} / \mathrm{cm}^{2}\right)$ for $5 \mathrm{~min} 2 \mathrm{~h}$ post-drug administration. ${ }^{* * * *} p<0.0001,{ }^{* * *} p<0.001$, ${ }^{* *} p<0.01,{ }^{*} p<0.05$ 
pathways. In conclusion, chemotherapy and PDT using PTX and IR780 had remarkable effects on the apoptosis and proliferation inhibition of A549 cells, and the multifunctional HA\&RBCm-LCNPs dramatically enhanced these antitumor effects.

In addition, although there was no significant difference in tumor volume and weight between LCNPs + NIR and RBCm-LCNPs + NIR, the RBCm-LCNPs + NIR group had more serious tumor cell apoptosis and less PCNA expression than those of the LCNPs + NIR group $(p<0.01)$. Besides, the expression of Caspase 3 in the tumor tissues of the RBCm-LCNPs + NIR group was significantly higher than that of the LCNPs + NIR group $(p<0.0001)$. These results indicate that $\mathrm{RBCm}$ coating enhanced the anti-tumor effect of PTX/IR780-LCNPs.

\section{Preliminary biosafety analysis}

With the exception of nude mice in the PTX Injection group, a slow increase in body weight was observed during the treatment period (Additional file 1: Figure S6). The nano-formulation groups had no appreciable effects on mouse body weight relative to the PTX Injection group.

The H\&E-stained tissue sections of the liver and lung in the saline group, PTX Injection group, and PTX/IR780LCNP group displayed multiple acute hepatocyte focal necrosis, small lesions in the lungs, and inflammatory cell infiltration after treatment (Fig. 11). Significant toxicity was not observed in the heart, spleen, and kidney. Multiple acute hepatocyte focal necrosis was also observed in the PTX/IR780-RBCm-LCNP group; however, there were no evident pathological changes in the lung tissue. This indicates that RBCm-LCNPs effectively reduced pathological changes in tissues. Notably, no noticeable pathological changes were present in the tissues of mice in the PTX/IR780-HA\&RBCm-LCNP group. The PTX Injection is typically prepared by dissolving paclitaxel in a polyoxyethylene castor oil and ethanol solvent mixture [76]. It has, however, been revealed that polyoxyethylene castor oil can induce various toxic reactions, such as gastrointestinal reactions, allergic reactions, hypotension, nephrotoxicity, cardiotoxicity, and myelosuppression [77]. Nevertheless, our findings confirmed that HA\&RBCm-LCNPs have the potential to improve the antitumor efficacy and biosafety of drugs.

\section{Conclusions}

The advantages of RBCs as coated nanoparticle carriers include: (a) a rich source and convenient preparation; (b) escape from the immune system to achieve extended circulation in vivo; (c) good biocompatibility and biodegradability; (d) reduced toxicity when used in certain nano-formulations; and (e) improved stability with reduced aggregation [78]. Although biomimetic

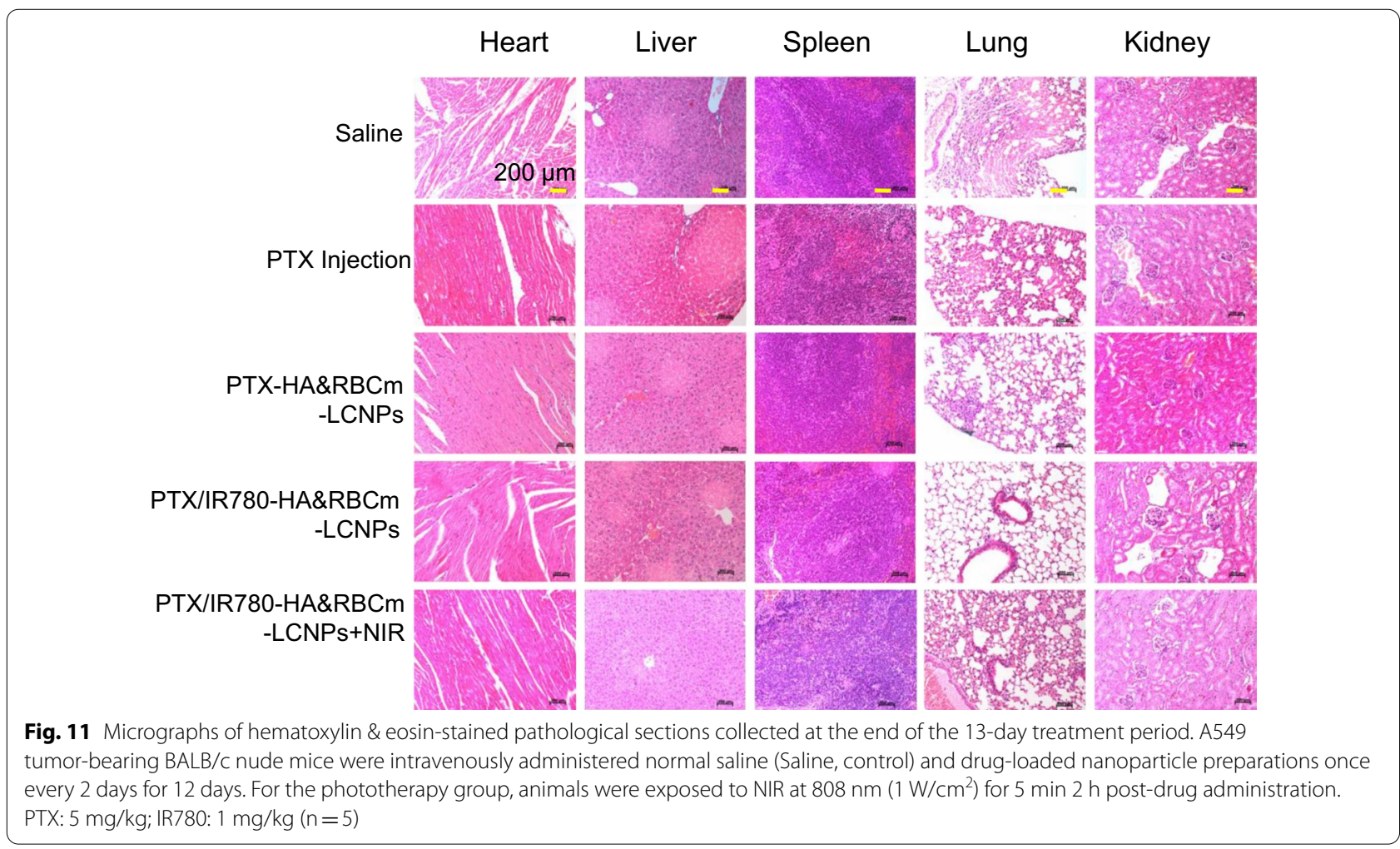


nanocarriers functionalized with erythrocyte membranes are potential competitors for chemically modified nanoparticles, the low tumor-targeting capacity of current drug delivery systems remains a limitation for clinical application. Therefore, the introduction of certain ligands and antibodies to confer active targeting is expected to improve targeted drug delivery in cancer therapy. In this study, by simply hybridizing HA and the erythrocyte membrane, the circulation in the blood was prolonged and accumulation in the tumor was enhanced. Moreover, the combination of chemotherapy and PDT mediated by PTX and low-dose IR780 achieved antitumor benefits and good biosafety, which was further significantly improved by co-loading these agents into HA\&RBCm-LCNPs. We also found that the combination of PTX and low-dose IR780 may have potential sensitization effects via the PI3K/Akt pathway, which would be conducive to reversing tumor resistance to PTX; however, further experimental verification is needed to explore this aspect of treatment. In addition, the interaction between PTX and IR780, their in vivo distribution, and their pharmacodynamics remain to be characterized. Nonetheless, we believe that the drug delivery system we describe here has the potential for safe and effective applicability in the clinic and should be explored and developed further.

\section{Materials and methods Materials}

PTX (API, purity >99\%) and IR780 iodide were purchased from Meilun Biotechnology Co., Ltd. (Dalian, China) and Merck KGaA (Darmstadt, Germany), respectively. PTX Injection (solution) was purchased from Jiangsu Osaikang Pharmaceutical Co., Ltd. (Nanjing, China). HA (240 kDa) was obtained from Freda Pharmaceutical Group Co., Ltd. (Jinan, China). Dioleoyl phosphoethanolamine (DOPE) and phosphatidylcholine (Lipoid S100) were purchased from Lipoid GmbH (Ludwigshafen, Germany). HA-DOPE was previously synthesized in our laboratory; the structure verification results are shown in Additional file 1: Figure S7 [79]. Glycerol dioleate was procured from Macklin Inc. (Shanghai, China). Western Blot Kit was purchased from Elabscience Biotechnology Co., Ltd. (Wuhan, China). Cell Counting Kit-8 (CCK-8) and DCFH-DA were obtained from Beyotime Biotechnology (Shanghai, China). SOSG and fetal bovine serum were purchased from ThermoFisher Scientific (New York, NY, USA). Other chemicals (for cell culture and labeling) were purchased from Jiangsu KeyGEN BioTECH Co., Ltd. (Nanjing, China) and Sinopharm Chemical
Reagent Co., Ltd. (Shanghai, China). Antibodies are listed in Additional file 1: Table S3.

\section{Animals and cell lines}

Healthy adult male Sprague-Dawley rats (weight, $200 \pm 20 \mathrm{~g}$ ) and male BALB/c nude mice (weight, $18 \pm 2 \mathrm{~g}$ ) were provided by the Experimental Animal Center of Shanghai University of Traditional Chinese Medicine. The experimental animal ethics committee approval numbers are PZSHUTCM8122104 and PZSHUTCM190301003.

Adenocarcinoma human alveolar basal epithelial cells (A549) were provided by the Shanghai Family Planning Research Institute (Shanghai, China). Mouse mononuclear macrophages (RAW264.7) were obtained from the Institute of Biochemistry and Cells, Chinese Academy of Sciences (Shanghai, China).

\section{Detection of PTX and IR780}

The amount of PTX in the samples were determined through ultra-performance liquid chromatography-mass spectrometry (UPLC-MS/MS, ThermoFisher Scientific). Thermo Syncronis C18 column $(50 \times 2 \mathrm{~mm}, 1.7 \mu \mathrm{m})$ was used at a column temperature of $40{ }^{\circ} \mathrm{C}$. Acetonitrile/0.1\% formic acid $(68: 32, \mathrm{v} / \mathrm{v})$ was used as the eluent at a flow rate of $0.3 \mathrm{~mL} / \mathrm{min}$. An electrospray ionization source was used for positive-ion detection. Settings for the remaining parameters are presented in Additional file 1: Table S4. The endogenous substances in biological samples did not interfere with the detection of PTX (Additional file 1: Figure S8), and specificity was deemed good. To assay the biological samples, a linear relationship was established between the peak area and the concentration of PTX with a range of $2-5000 \mathrm{ng} / \mathrm{mL}(\mathrm{r}=0.9999)$, with an extraction recovery of more than $90 \%$.

IR780 was detected using a UV-Vis Cary 8454 instrument (Agilent Technologies Inc., Santa Clara, CA, USA) at a wavelength of $780 \mathrm{~nm}$. The IR780 concentration in the range of $0.25-5 \mu \mathrm{g} / \mathrm{mL}$ showed a linear relationship $(r=0.999)$ with the absorbance, and IR780 was recovered at a rate of $>90 \%$.

\section{LCNP preparation}

Glycerol dioleate (166 mg), Lipoid S100 (86 mg), Tween 80 (75 mg), ethanol (50 mg), PTX (30 mg), and IR780 (6 mg) were mixed and stirred using a magnetic stirrer at $150 \times g$ for $24 \mathrm{~h}$ to obtain a uniform oil phase. The mixture was then slowly added to deionized water (10 $\mathrm{mL}$ ), with magnetic stirring at $400 \mathrm{rpm}$ for $24 \mathrm{~h}$. A probe ultrasound (195 W) (JY92-IIN, Scientz Biotechnology Co., Ltd., Ningbo, China) was used for $10 \mathrm{~min}$ for LCNP formation. 


\section{$\mathrm{RBCm}$-derived vesicle preparation}

The preparation of $\mathrm{RBCm}$-derived vesicles is described in Fig. 2A. Briefly, fresh rat blood was centrifuged at $1000 \times g$ for $10 \mathrm{~min}$. Blood cells were collected and added to phosphate-buffered saline (PBS; pH 7.4). After sufficient hemolysis, cells were centrifuged, and the precipitate was washed with PBS until a colorless supernatant was obtained. The resulting $\mathrm{RBCm}$ were resuspended in PBS, extruded with using a mini extruder (Avanti Polar Lipids, Inc., Alabaster, AL, USA), and filtered with 1,000nm, 800-nm, 400-nm, and 200-nm Track-Etch membranes (GE Healthcare Life Sciences, Buckinghamshire, UK). Samples were then pressed back and forth 10 times to obtain uniform $\mathrm{RBCm}$-derived vesicles, as previously described [71]. HA-DOPE was mixed with RBCm vesicles for $30 \mathrm{~min}$, and excess free HA-DOPE was removed via centrifugation to obtain $H A \& R B C m$.

\section{RBCm-LCNP and HA\&RBCm-LCNP preparation}

LCNPs were mixed with $\mathrm{RBCm}$ and HA\&RBCm, sonicated for $5 \mathrm{~min}$ in a water bath, and extruded through 400-nm and 200-nm Track-Etch membranes using a mini extruder. Samples were then pressed back and forth ten times to obtain RBCm-LCNPs and HA\&RBCm-LCNPs (Fig. 2A), as previously described [80].

\section{Drug loading and encapsulation efficiency}

The preparation was added to an ultrafiltration tube (molecular weight cut-off: $100 \mathrm{kDa}$ ), centrifuged to dryness at $3000 \times g$, and washed twice with water. The filtrate was assayed, and the drug amount was recorded as $\mathrm{W}_{\mathrm{f}}$, while the drug in the nano-formulations was extracted using 9 volumes $(\mathrm{v} / \mathrm{v})$ of methanol to determine the total drug amount $\left(\mathrm{W}_{\mathrm{t}}\right)$ in the preparation. The amount of lipid excipients was labeled as $\mathrm{W}_{\mathrm{n}}$. Drug loading and encapsulation efficiency were calculated using Eqs. 1 and 2, respectively, as follows:

$$
\begin{aligned}
& \text { Drug loading }=\frac{W_{t}-W_{f}}{W_{n}+W_{t}} \times 100 \% \\
& \text { Encapsulation efficiency }=\frac{W_{t}-W_{f}}{W_{t}} \times 100 \%
\end{aligned}
$$

\section{Determination of particle size and zeta potential}

The particle size distribution of the nanoparticles was measured at $25{ }^{\circ} \mathrm{C}$ using the dynamic light scattering method. Zeta potential was also measured (Nano ZS90; Malvern Panalytical Company, Malvern, UK). Each test was performed in triplicate.
Transmission electron microscope imaging

The preparation was diluted $60-$ fold $(\mathrm{v} / \mathrm{v})$ with deionized water and dripped onto a copper mesh. The preparation was dyed with $2 \%$ phosphotungstic acid for $30 \mathrm{~s}$ and observed using a transmission electron microscope (TEM; JEM-2100; JEOL Ltd., Tokyo, Japan).

The internal structures of the prepared nanoparticles were observed using a Tecnai G2 F20 cryo-transmission electron microscope (cryo-TEM; FEI, Hillsborough, OR, USA). The liquid sample was dropped onto the hydrophilized lacey copper mesh and frozen in glacial ethane. Cryo-TEM imaging was performed using a TEM operating at $200 \mathrm{kV}$.

\section{Protein detection}

Radioimmunoprecipitation assay (RIPA) cell lysis buffer was added to RBCs, RBCm, RBCm-LCNPs, and HA\&RBCm-LCNPs. Subsequently, they were lysed on ice for $30 \mathrm{~min}$ and vortexed for $10 \mathrm{~s}$ every $10 \mathrm{~min}$. After $30 \mathrm{~min}$, the supernatant (total protein solution) was centrifuged at $10,994 \times g$ for $10 \mathrm{~min}$ at $4{ }^{\circ} \mathrm{C}$. Sample loading buffer was added, the samples were mixed well, centrifuged, and boiled for $5 \mathrm{~min}$ for protein denaturation. The obtained sample was processed according to the general procedure for SDS-PAGE and western blotting analysis.

\section{In vitro release}

The preparation was added to a dialysis bag (molecular weight cutoff: $14,000 \pm 2000 \mathrm{Da})$, and $15 \%(\mathrm{w} / \mathrm{v})$ 2-hydroxypropyl- $\beta$-cyclodextrin in PBS was used as a release medium to maintain the sink condition during shaking at $37^{\circ} \mathrm{C}$. Samples were collected at different time points; meanwhile, an equal volume of fresh release medium was added. Paclitaxel and IR780 in the samples were subsequently detected.

\section{Photothermal effects}

The test preparation was diluted with water to IR780 final concentration of $20 \mu \mathrm{g} / \mathrm{mL}$ and $60 \mu \mathrm{g} / \mathrm{mL}$, and $1 \mathrm{~mL}$ of each sample was added to each well of a transparent 24-well plate. Pure water was used as the control. Samples were exposed to NIR at $808 \mathrm{~nm}\left(1 \mathrm{~W} / \mathrm{cm}^{2}\right)$ using a laser generator (MDL-FC-808 nm; Inter-Diff Technology Co., Ltd, Shanghai, China). The temperature of the solution was recorded using an infrared ray thermometer (MC-872; OMRON Corporation, Kyoto, Japan). Each experiment was performed independently three times.

\section{Singlet oxygen detection}

Two hundred microliters of pure water (Control) or nanocarrier solution with different concentrations 
of IR780 and $20 \mu \mathrm{L}$ of SOSG $(50 \mu \mathrm{M})$ were added to a 96-well plate and exposed to NIR at $808 \mathrm{~nm}\left(1 \mathrm{~W} / \mathrm{cm}^{2}\right)$. The fluorescence intensity of the solution in each well was detected using a fluorescent microplate reader (Ex/ $\mathrm{Em}=504 \mathrm{~nm} / 525 \mathrm{~nm}$; Spark $10 \mathrm{M}$; Tecan, Männedorf, Switzerland). Each experiment was performed three times.

\section{Stability in the plasma}

Each preparation was separately added to an equal volume of rat plasma before incubation at $37^{\circ} \mathrm{C}$. Samples were retrieved at predetermined time points to determine the change in particle size. Each experiment was conducted in triplicate.

\section{Hemolysis assay}

When hemolysis occurs, hemoglobin escapes from the broken red blood cells, and the solution appears red, so hemolysis can be evaluated based on color changes of the solution. Fresh rat blood was collected in a centrifuge tube pretreated with heparin sodium, centrifuged at $1000 \times g$ for $10 \mathrm{~min}$ at $4{ }^{\circ} \mathrm{C}$ to retrieve RBCs, which were washed with normal saline and diluted to $2 \%(\mathrm{v} / \mathrm{v})$ $\mathrm{RBC}$ suspension. Equal volume of preparations diluted in normal saline, normal saline (negative control), and $1 \%$ Triton X-100 (positive control) were also prepared.

\section{Nanoparticle uptake by $\mathrm{A} 549$ cells}

A549 cells were seeded at a density of $1 \times 10^{5}$ cells/well in 6-well plates (for flow cytometry detection; Corning Incorporated, Corning, NY, USA) or in glass-bottom dishes (for imaging; Wuxi NEST Biotechnology, Wuxi, China) and cultured for $24 \mathrm{~h}$ before incubation with fresh Dulbecco's modified Eagle medium containing $10 \%$ fetal bovine serum, $1 \%$ penicillin and streptomycin (blank control group) or C6-labeled formulation (final concentration of $1 \mu \mathrm{g} / \mathrm{mL}$ diluted in the medium). The mixture was incubated at $37{ }^{\circ} \mathrm{C}$ for $2 \mathrm{~h}$. Thereafter, the samples were subjected to the following analyses: (a) the fluorescence intensity of cells was measured using FACS using a flow cytometer (FACS-Canto; Becton, Dickinson and Company, Lake Franklin, NJ, USA); and (b) cells were fixed with $4 \%$ paraformaldehyde for 20 min, stained with DAPI for $8 \mathrm{~min}$, and observed using a CLSM (TCSSP8; Leica, Wetzlar, Germany) within $2 \mathrm{~h}$. Ex/Em values were $415 \mathrm{~nm} / 485 \mathrm{~nm}$ and 498 $\mathrm{nm} / 568 \mathrm{~nm}$, respectively. Each experiment was carried out in triplicate.
Cytotoxicity, apoptosis, reactive oxygen species, and tubulin expression assays

A549 cells were seeded at a density of $5 \times 10^{3}$ cells/well in 96-well plates (Corning Incorporated) for the cytotoxicity assay; $2 \times 10^{5}$ cells/well in 6-well plates for apoptosis determination using flow cytometry; and $1 \times 10^{5}$ cells/ well in glass-bottom dishes for apoptosis, ROS, and tubulin assays using a CLSM. Cells were cultured at $37{ }^{\circ} \mathrm{C}$ in $5 \% \mathrm{CO}_{2}$ for $24 \mathrm{~h}$ and incubated with fresh medium (control group). Each preparation that was diluted with fresh medium (for ROS detection, tubulin analysis, and apoptosis assay, the final PTX and IR780 concentrations were $5 \mu \mathrm{g} / \mathrm{mL}$ and $1 \mu \mathrm{g} / \mathrm{mL}$, respectively) was added to cells and incubated for $24 \mathrm{~h}$. For the phototherapy group, cells were exposed to NIR at $808 \mathrm{~nm}\left(1 \mathrm{~W} / \mathrm{cm}^{2}\right)$ for $5 \mathrm{~min}$ $2 \mathrm{~h}$ post-drug administration. Thereafter, the following detections were performed separately:

For the cytotoxicity assay, $10 \mu \mathrm{L}$ of the CCK- 8 reagent was added to each well prior to a 1 -h incubation period. Absorbance at a wavelength of $450 \mathrm{~nm}$ was measured using a microplate reader. Cell viability was calculated using Eq. 3.

$$
\text { Cell viability }=\frac{O D_{\text {preparation }}-O_{\text {blank }}}{O D_{\text {cell }}-O_{\text {blank }}} \times 100 \%
$$

$\mathrm{OD}_{\text {preparation }}, \mathrm{OD}_{\text {cell }}$, and $\mathrm{OD}_{\text {blank }}$ represent the absorbance of cells treated with the test preparations, absorbance of the cells that were not treated with preparations, and absorbance of the medium containing no cells, respectively.

For the apoptosis assay, samples underwent the following processing and corresponding testing: (a) cells were fixed in $4 \%$ paraformaldehyde in PBS, then incubated with Hoechst $33342(5 \mu \mathrm{g} / \mathrm{mL})$ for $5 \mathrm{~min}$, and observed using a CLSM $(E x / E m=415 \mathrm{~nm} / 485 \mathrm{~nm})$; (b) cells were digested with EDTA-free trypsin and suspended in $100 \mu \mathrm{L}$ of binding buffer, and $5 \mu \mathrm{L}$ of Annexin V-FITC was added to the sample prior to incubation at $4{ }^{\circ} \mathrm{C}$ for $30 \mathrm{~min}$. Four hundred microliters of binding buffer and 5 $\mu \mathrm{L}$ of propidium iodide (PI) solution were subsequently added. The mixture was incubated for $5 \mathrm{~min}$ at $4{ }^{\circ} \mathrm{C}$ and assayed via flow cytometry (FITC, Ex/Em $=490 \mathrm{~nm} / 515$ $\mathrm{nm}$; PI, Ex/Em=535 nm/617 nm). For the ROS assay, cells were incubated with DCFH-DA $(10 \mathrm{nmoL} / \mathrm{mL})$ for $30 \mathrm{~min}$ and imaged using a CLSM $(\mathrm{Ex} / \mathrm{Em}=488 \mathrm{~nm} / 525$ $\mathrm{nm})$.

For the tubulin distribution assay, cells were fixed in $4 \%$ paraformaldehyde in PBS for $20 \mathrm{~min}$ and treated sequentially with $3 \% \mathrm{H}_{2} \mathrm{O}_{2}$ for $10 \mathrm{~min}, 10 \%$ goat serum 
for $30 \mathrm{~min}$, anti- $\alpha$-tubulin antibody $(1: 1,000)$ for $90 \mathrm{~min}$, FITC-labeled antibody for $60 \mathrm{~min}$, and DAPI for $10 \mathrm{~min}$. Samples were immediately imaged using a CLSM (Ex/ $\mathrm{Em}=590 \mathrm{~nm} / 617 \mathrm{~nm}$ ).

\section{Cell migration assay}

A549 cells were seeded in a 6-well plate at a density of $5 \times 10^{5}$ cells/well and cultured in $5 \% \mathrm{CO}_{2}$ at $37{ }^{\circ} \mathrm{C}$ for $24 \mathrm{~h}$. The culture medium was removed, and the cells were subjected to a cell-scratch test. Two milliliters of incomplete medium (control group) and the preparations, diluted with incomplete medium, containing a final concentration of $2.5 \mu \mathrm{g} / \mathrm{mL}$ paclitaxel and $0.5 \mu \mathrm{g} /$ $\mathrm{mL}$ IR780, were added to the wells. In the phototherapy group, after $2 \mathrm{~h}$ of drug administration, cells were exposed to NIR at $808 \mathrm{~nm}\left(1 \mathrm{~W} / \mathrm{cm}^{2}\right)$ for $5 \mathrm{~min}$. Scratches were observed with a microscope (DMi1; Leica) after 0 and $24 \mathrm{~h}$. ImageJ (NIH, Bethesda, MD, USA) was used for statistical analysis of migration distance. Thereafter, cells were collected, and the related proteins were assayed through western blotting. Each experiment was performed in triplicate.

\section{Immunogenicity test}

RAW264.7 cells were seeded at a density of $3 \times 10^{5}$ cells/well; the assays were performed as described in the nanoparticle uptake assays were performed as aforementioned.

\section{Establishment of xenograft model in nude mice}

Each nude mouse received a subcutaneous injection of $5 \times 10^{6}$ cells. Equation 4 was used to calculate the volume of transplanted tumors in nude mice:

$$
\mathrm{V}=\frac{\mathrm{L} \times \mathrm{W}^{2}}{2}
$$

where V represents tumor volume $\left(\mathrm{mm}^{3}\right)$, and $\mathrm{L}$ and $\mathrm{W}$ represent long and short tumor diameters $(\mathrm{mm})$, respectively.

\section{Pharmacokinetics}

Test preparations were intravenously injected into rats with PTX and IR780 doses of 5 and $1 \mathrm{mg} / \mathrm{kg}$, respectively. Blood was sampled, and the separated plasma was mixed with a 1:10 volume of docetaxel solution $(5 \mu \mathrm{g} / \mathrm{mL}$; internal standard). Drug was extracted using methyl tert-butyl ether and detected through UPLC-MS/MS. DAS2.0 software was used to calculate pharmacokinetic parameters.

\section{Label-free quantitative proteomic analysis of protein coronas}

The LCNP and HA\&RBCm-LCNP solutions were separately incubated with plasma $(1: 1, v / v)$ at $37{ }^{\circ} \mathrm{C}$ for $1 \mathrm{~h}$, then centrifuged at $6000 \times g$ for $15 \mathrm{~min}$ to obtain nanocarrier-protein complexes. The resulting complexes were washed with PBS to remove unbound proteins, digested with protein lysis buffer, and supplemented with PMSF $(1 \mathrm{mM})$. After shaking for $30 \mathrm{~min}$, the solution was centrifuged at $12,000 \times g$ for $10 \mathrm{~min}$ at $4{ }^{\circ} \mathrm{C}$. Dithiothreitol ( 5 $\mathrm{mM}$ ) was mixed with $50 \mu \mathrm{g}$ of protein from each sample, incubated at $55{ }^{\circ} \mathrm{C}$ for $30 \mathrm{~min}$, and cooled to room temperature on ice. Then, iodoacetamide was added to the pellet to a final concentration of $10 \mathrm{mM}$ and incubated in the dark for $15 \mathrm{~min}$. Acetone was added and the mixture was centrifuged at $8000 \times g$ at $4{ }^{\circ} \mathrm{C}$ for $10 \mathrm{~min}$. The precipitate was dissolved in $100 \mu \mathrm{L}$ of triethylamonium bicarbonate, and proteins were digested with trypsin. The peptides were desalted using a SOLA $\mu$ SPE 96-Well Plate (ThermoFisher Scientific), eluted with 60\% methanol, and evaporated in vacuo. The samples were analyzed using ThermoFisher Scientific EASY-nLC 1200 and Q Exactive HF systems with a liquid chromatography column (ThermoFisher Scientific Acclaim PepMap RSLC C18; $75 \mu \mathrm{m}$ $\times 150 \mathrm{~mm}, 2 \mu \mathrm{m}, 100 \AA$ ). The mobile phase compositions were: phase $\mathrm{A}, \mathrm{H}_{2} \mathrm{O}$-formic acid (99.9:0.1, v/v); and phase B, acetonitrile- $\mathrm{H}_{2} \mathrm{O}$-formic acid (80:19.9:0.1, v/v/v). The gradient elution procedure was set to $0-82 \mathrm{~min}, 5-44 \%$ B; $82-84 \mathrm{~min}, 44-90 \% \mathrm{~B}$; and $84-90 \mathrm{~min}, 90 \% \mathrm{~B}$. The mass resolution of the first-order mass spectrometry (MS) was set to 120,000 ; the $\mathrm{m} / \mathrm{z}$ was set to $350-1650$ for a full scan; and 20 of the main peaks were scanned by MS/MS in positive-ion mode with a resolution of 30,000. Label-free quantification was performed using MaxQuant (version number 1.5.2.8; Max-Planck-Institute of Biochemistry, Planegg, Germany) with Andromeda. The search conditions were controlled by false discovery rate, and the values that did not meet the analytical standards were filtered out using a reverse database and common contaminant database. The specific retrieval parameter settings are listed in Additional file 1: Table S5.

\section{Biodistribution}

Tumor-bearing nude mice with similar body weights and tumor volume were randomly divided into groups. The preparations of paclitaxel and IR780 were intravenously administered at doses of 5 and $1 \mathrm{mg} / \mathrm{kg}$, respectively; normal saline was administered to the control group (saline). Six hours following administration, the blood, heart, liver, spleen, lung, kidney, and tumor tissues were 
removed and weighed. Tissue samples were mixed three times $(\mathrm{m} / \mathrm{v})$ with dimethyl sulfoxide in normal saline $(10 \%, \mathrm{v} / \mathrm{v})$ and homogenized. The homogenate was centrifuged at $4000 \times g$ for $10 \mathrm{~min}$. Thereafter, $100 \mu \mathrm{L}$ of the supernatant was taken, and $10 \mu \mathrm{L}$ of docetaxel solution $(5 \mu \mathrm{g} / \mathrm{mL})$ was added as an internal standard. Subsequent steps were the same as those described in pharmacokinetics assay.

IR780 fluorescence was recorded at predetermined time points using a live imaging system (Ex/Em: 740 $\mathrm{nm} / 804 \mathrm{~nm}$; IVIS Lumina XR; Caliper Life Sciences, Hopkinton, MA, USA) $72 \mathrm{~h}$ post-injection. The fluorescence distribution of removed tissues was also imaged.

\section{In vivo antitumor effects}

Tumor-bearing nude mice (tumor volume approximately $50 \mathrm{~mm}^{3}$ ) were randomly assigned to one of the treatment groups or the control group. Mice were intravenously administered PTX/IR780-loaded nanocarriers (5 mg/ $\mathrm{kg}$ and $1 \mathrm{mg} / \mathrm{mL}$ doses of PTX and IR780, respectively) and PTX-loaded preparations $(5 \mathrm{mg} / \mathrm{kg}$ dose of paclitaxel) once every 2 days for 12 days. For the phototherapy group, mice were exposed to NIR at $808 \mathrm{~nm}(1 \mathrm{~W} /$ $\mathrm{cm}^{2}$ ) for $5 \mathrm{~min}$ after $2 \mathrm{~h}$ of drug administration. Tumor volume and body weight were measured every 2 days. On the second day following the final administration, the tumor was removed and weighed. Thereafter, the heart, liver, spleen, lung, and kidney were removed. Tissues were fixed with $4 \%$ paraformaldehyde for $48 \mathrm{~h}$, embedded in paraffin, and separately subjected to the following assays or staining: (a) hematoxylin \& eosin staining; (b) TUNEL assay according to manufacturer's instructions; and (c) PCNA assay. For PCNA assay, the tissues were sectioned, dewaxed, and subjected to gradient ethanol hydration. The slices were treated with tris-EDTA ( 1 mmoL, $\mathrm{pH}$ 8.0) and $\mathrm{H}_{2} \mathrm{O}_{2}$; incubated with a primary antibody (1:100; PCNA; overnight reaction at $\left.4{ }^{\circ} \mathrm{C}\right)$ and secondary antibody $\left(30 \mathrm{~min}\right.$ at $\left.37^{\circ} \mathrm{C}\right)$; and then stained with diaminobenzidine and hematoxylin. Tissue slices were observed via microscopy. ImageJ was used for the semi-quantitative analysis of images. In addition, Bcl2 , Bax, and caspase-3 expression levels in tumor tissues were assayed through western blotting.

\section{Statistical analysis}

One-way analysis of variance was performed using SPSS 19.0 software (IBM, Armonk, NY, USA). A $p$ value $<0.05$ indicates statistical difference.

\section{Supplementary Information}

The online version contains supplementary material available at https://doi. org/10.1186/s12951-021-00977-3.
Additional file 1: Figure S1. Characteristics and blood compatibility of the prepared nano-formulations. Figure $\mathbf{S 2}$. In vitro release of PTX and IR780 from the PTX/IR780-loaded LCNPS, RBCm-LCNPs, and HA\&RBCmLCNPs $(n=3)$. Figure S3. Characteristics of IR780 in aqueous solution and in nanocarriers. Figure S4. In vitro A549 cell viability following treatment with PTX/IR780-loaded RBCm-LCNPs (PTX/IR780-RBCm-LCNPs), and HA\&RBCm-LCNPs (PTX/IR780-HA\&RBCm-LCNPs) with different concentrations of total PTX and IR780; "+ NIR" refers to near infrared irradiation; the concentration of Blank HA\&RBCm-LCNPs is correspond to PTX/IR780loaded formulations $(n=3)$. Figure S5. In vivo rat plasma concentrationtime profiles of PTX following intravenous injection of PTX and IR780 aqueous solution (PTX/IR780-solution), PTX/IR780-loaded LCNPs (PTX/ IR780-LCNPs), RBCm-LCNPS (PTX/IR780-RBCm-LCNPs), and HA\&RBCmLCNPs (PTX/IR780-HA\&RBCm-LCNPs); the dose of PTX and IR780 were respectively as $5 \mathrm{mg} / \mathrm{kg}$ and $1 \mathrm{mg} / \mathrm{kg}$. Data are presented as mean $\pm \mathrm{SD}$ $(n=6)$. Figure S6. Body weight changes of A549 tumor-bearing Balb/cnu mice during treatment period. Figure S7. FT-IR spectra of HA, DOPE, and HA-DOPE. Figure S8. UPLC-MS/MS chromatograms of (A) blank plasma, (B) blank plasma mixed with PTX and docetaxel (DTX), and (C) plasma sample collected from rats following intravenous administration of commercial PTX injection. Table S1. Statistics ofadministration methods of IR780 for phototherapy in representative papers published in 2020. Table S2. The IC50 of PTX/IR780 preparations against A549 cells in vitro $(n=3)$. Table S3. Antibodies used in the current work. Table S4. Mass spectrometry parameter settings. Table S5. Retrieval parameters of mass spectrum.

Additional file 2. Data of label-free quantitative proteomic analysis of protein coronas.

\section{Acknowledgements}

We thank the Electron Microscopy System at National Facility for Protein Science in Shanghai, Zhangjiang Lab, Shanghai Advanced Research Institute, Chinese Academy of Sciences for Cryo-TEM analysis and especially Duan Jialin and Li Guangyi for their help in making samples and taking pictures.

\section{Authors' contributions}

Conceptualization: YZ; Data curation: QX; Formal analysis: YH; Funding acquisition and Investigation: YZ; Methodology: ZH and YL; Project administration: QX and TW; Resources: NF; Software: XH; Supervision: YZ and NF; Validation: SR; Visualization: ZL, CZ, and JS; Roles/Writing —original draft: YZ; Writing—review \& editing: NF. YZ, QX, and TW contributed equally to this work. All authors read and approved the final manuscript.

\section{Funding}

This work was financially supported by the National Natural Science Foundation of China $(82074031,82074279)$, the Natural Science Foundation of Shanghai (20ZR1458300), the Funds for Training Key Talents of Traditional Chinese Medicine from the State Administration of Traditional Chinese Medicine (T20194828003), Shanghai Talent Development Fund (2018099), Special Funding for Shanghai Oriental Scholar Distinguished Professor (TP2020054), and sponsored by Shanghai Sailing Program (21YF1447400).

\section{Availability of data and materials}

The datasets used and analyzed during the current study are available from the corresponding author on reasonable request.

\section{Declarations}

Ethics approval and consent to participate

Not applicable.

\section{Consent for publication}

Not applicable.

\section{Competing interests}

The authors declare that they have no competing interests. 


\section{Author details}

${ }^{1}$ Department of Pharmaceutical Sciences, Shanghai University of Traditional Chinese Medicine, Shanghai 201203, China. ${ }^{2}$ Teaching Experiment Center, Shanghai University of Traditional Chinese Medicine, Shanghai 201203, China.

Received: 29 April 2021 Accepted: 27 July 2021

Published online: 14 August 2021

\section{References}

1. Sung H, Ferlay J, Siegel RL, Laversanne M, Soerjomataram I, Jemal A, et al. Global cancer statistics 2020: GLOBOCAN estimates of incidence and mortality worldwide for 36 cancers in 185 countries. CA Cancer J Clin. 2021. https://doi.org/10.3322/caac.21660.

2. Alshaer W, Hillaireau H, Fattal E. Aptamer-guided nanomedicines for anticancer drug delivery. Adv Drug Deliv Rev. 2018;134:122-37.

3. Chen W, Zeng K, Liu H, Ouyang J, Wang L, Liu Y, et al. Cell membrane camouflaged hollow prussian blue nanoparticles for synergistic photothermal-/chemotherapy of cancer. Adv Funct Mater. 2017;27:1605795.

4. Lin A, Liu Y, Zhu X, Chen X, Liu J, Zhou Y, et al. Bacteria-responsive biomimetic selenium nanosystem for multidrug-resistant bacterial infection detection and inhibition. ACS Nano. 2019;13:13965-84.

5. Liu B, Hu F, Zhang J, Wang C, Li L. A biomimetic coordination nanoplatform for controlled encapsulation and delivery of drug-gene combinations. Angew Chem Int Ed Engl. 2019;58:8804-8.

6. Tonigold M, Simon J, Estupiñán D, Kokkinopoulou M, Reinholz J, Kintzel $U$, et al. Pre-adsorption of antibodies enables targeting of nanocarriers despite a biomolecular corona. Nat Nanotechnol. 2018;13:862-9.

7. Guan J, Shen Q, Zhang Z, Jiang Z, Yang Y, Lou M, et al. Enhanced immunocompatibility of ligand-targeted liposomes by attenuating natural lgM absorption. Nat Commun. 2018;9:2982.

8. Børresen B, Henriksen JR, Clergeaud G, Jørgensen JS, Melander F, Elema $D R$, et al. Theranostic imaging may vaccinate against the therapeutic benefit of long circulating PEGylated liposomes and change Cargo pharmacokinetics. ACS Nano. 2018;12:11386-98.

9. Mohamed M, Abu Lila AS, Shimizu T, Alaaeldin E, Hussein A, Sarhan HA, et al. PEGylated liposomes: immunological responses. Sci Technol Adv Mater. 2019;20:710-24.

10. Shimizu T, Ishida T, Kiwada H. Transport of PEGylated liposomes from the splenic marginal zone to the follicle in the induction phase of the accelerated blood clearance phenomenon. Immunobiology. 2013;218:725-32.

11. Abu Lila AS, Kiwada H, Ishida T. The accelerated blood clearance (ABC) phenomenon: clinical challenge and approaches to manage. J Control Release. 2013;172:38-47.

12. Zhang $X$, Angsantikul $P$, Ying $M$, Zhuang J, Zhang $Q$, Wei $X$, et al. Remote loading of small-molecule therapeutics into cholesterol-enriched cellmembrane-derived vesicles. Angew Chem Int Ed Engl. 2017;56:14075-9.

13. Lejeune A, Moorjani M, Gicquaud C, Lacroix J, Poyet P, Gaudreault R. Nanoerythrosome, a new derivative of erythrocyte ghost: preparation and antineoplastic potential as drug carrier for daunorubicin. Anticancer Res. 1994;14:915-9.

14. Fang $\mathrm{RH}$, Hu CM, Zhang L. Nanoparticles disguised as red blood cells to evade the immune system. Expert Opin Biol Ther. 2012;12:385-9.

15. Luk BT, Fang RH, Hu CM, Copp JA, Thamphiwatana S, Dehaini D, et al. Safe and immunocompatible nanocarriers cloaked in rbc membranes for drug delivery to treat solid tumors. Theranostics. 2016;6:1004-11.

16. Liu JM, Zhang DD, Fang GZ, Wang S. Erythrocyte membrane bioinspired near-infrared persistent luminescence nanocarriers for in vivo longcirculating bioimaging and drug delivery. Biomaterials. 2018;165:39-47.

17. Xia Q, Zhang Y, Li Z, Hou X, Feng N. Red blood cell membrane-camouflaged nanoparticles: a novel drug delivery system for antitumor application. Acta Pharm Sin B. 2019;9:675-89.

18. Price LSL, Stern ST, Deal AM, Kabanov AV, Zamboni WC. A reanalysis of nanoparticle tumor delivery usingclassical pharmacokinetic metrics. Sci Adv. 2020;6:eaay9249.

19. Vijayan V, Uthaman S, Park IK. Cell membrane coated nanoparticles: an emerging biomimetic nanoplatform for targeted bioimaging and therapy. Adv Exp Med Biol. 2018;1064:45-59.
20. He S, Fan W, Wu N, Zhu J, Miao Y, Miao X, et al. Lipid-based liquid crystalline nanoparticles facilitate cytosolic delivery of siRNA via structural transformation. Nano Lett. 2018;18:2411-9.

21. Ahmed KS, Hussein SA, Ali AH, Korma SA, Lipeng Q, Jinghua C. Liposome: composition, characterisation, preparation, and recent innovation in clinical applications. J Drug Target. 2019;27:742-61.

22. Freag MS, Elnaggar YS, Abdelmonsif DA, Abdallah OY. Stealth, biocompatible monoolein-based lyotropic liquid crystalline nanoparticles for enhanced aloe-emodin delivery to breast cancer cells: in vitro and in vivo studies. Int J Nanomed. 2016;11:4799-818.

23. Hu B, Ma Y, Yang Y, Zhang L, Han H, Chen J. CD44 promotes cell proliferation in non-small cell lung cancer. Oncol Lett. 2018;15:5627-33.

24. Rios de la Rosa JM, Tirella A, Gennari A, Stratford IJ, Tirelli N. The CD44mediated uptake of hyaluronic acid-based carriers in macrophages. Adv Healthc Mater. 2017. https://doi.org/10.1002/adhm.201601012.

25. Choi KY, Han HS, Lee ES, Shin JM, Almquist BD, Lee DS, et al. Hyaluronic acid-based activatable nanomaterials for stimuli-responsive imaging and therapeutics: beyond CD44-mediated drug delivery. Adv Mater. 2019;31:e1803549.

26. Barauskas J, Johnsson M, Tiberg F. Self-assembled lipid superstructures: beyond vesicles and liposomes. Nano Lett. 2005;5:1615-9.

27. Cervin C, Tinzl M, Johnsson M, Abrahamsson PA, Tiberg F, Dizeyi N. Properties and effects of a novel liquid crystal nanoparticle formulation of docetaxel in a prostate cancer mouse model. Eur J Pharm Sci. 2010;41:369-75.

28. Chen ZA, Wu SH, Chen P, Chen YP, Mou CY. Critical features for mesoporous silica nanoparticles encapsulated into erythrocytes. ACS Appl Mater Interfaces. 2019;11:4790-8.

29. Sun Q, Kang Z, Xue L, Shang Y, Su Z, Sun H, et al. A collaborative assembly strategy for tumor-targeted siRNA delivery. J Am Chem Soc. 2015;137:6000-10.

30. Brown E. Integrin-associated protein (CD47): an unusual activator of G protein signaling. J Clin Invest. 2001;107:1499-500.

31. Oldenborg PA, Zheleznyak A, Fang YF, Lagenaur CF, Gresham HD, Lindberg FP. Role of CD47 as a marker of self on red blood cells. Science. 2000;288:2051-4

32. Barclay AN, Van den Berg TK. The interaction between signal regulatory protein alpha (SIRPa) and CD47: structure, function, and therapeutic target. Annu Rev Immunol. 2014;32:25-50.

33. Kroll AV, Fang RH, Zhang L. Biointerfacing and applications of cell membrane-coated nanoparticles. Bioconjug Chem. 2017;28:23-32.

34. Leesajakul W, Nakano M, Taniguchi A, Handa T. Interaction of cubosomes with plasma components resulting in the destabilization of cubosomes in plasma. Colloids Surf B Biointerfaces. 2004;34:253-8.

35. Zhang Y, Zhang H, Zhang K, Li Z, Guo T, Wu T, et al. Co-hybridized composite nanovesicles for enhanced transdermal eugenol and cinnamaldehyde delivery and their potential efficacy in ulcerative colitis. Nanomedicine. 2020;28:102212.

36. Schönermark S, Rauterberg EW, Shin ML, Löke S, Roelcke D, Hänsch GM. Homologous species restriction in lysis of human erythrocytes: a membrane-derived protein with C8-binding capacity functions as an inhibitor. J Immunol. 1986;136:1772-6.

37. Hu CM, Fang RH, Zhang L. Erythrocyte-inspired delivery systems. Adv Healthc Mater. 2012;1:537-47.

38. Zheng Y, Hou G, Zhang G, Lan T, Yuan J, Zhang L, et al. The near-infrared fluorescent dye IR-780 was coupled with cabazitaxel for castrationresistant prostate cancer imaging and therapy. Invest New Drugs. 2020;38:1641-52.

39. Qin W, Quan G, Sun Y, Chen M, Yang P, Feng D, et al. Dissolving microneedles with spatiotemporally controlled pulsatile release nanosystem for synergistic chemo-photothermal therapy of melanoma. Theranostics. 2020;10:8179-96.

40. Yu Q, Qiu Y, Li J, Tang X, Wang X, Cun X, et al. Targeting cancer-associated fibroblasts by dual-responsive lipid-albumin nanoparticles to enhance drug perfusion for pancreatic tumor therapy. J Control Release. 2020;321:564-75.

41. Kenry, Duan Y, Liu B. Recent advances of optical imaging in the second near-infrared window. Adv Mater. 2018;30:e1802394. 
42. Ng KK, Weersink RA, Lim L, Wilson BC, Zheng G. Controlling spatial heat and light distribution by using photothermal enhancing auto-regulated liposomes (PEARLs). Angew Chem Int Ed Engl. 2016;55:10003-7.

43. Chen Q, Hu Q, Dukhovlinova E, Chen G, Ahn S, Wang C, et al. Photothermal therapy promotes tumor infiltration and antitumor activity of CART cells. Adv Mater. 2019;31:e1900192.

44. Zhao $\mathrm{H}$, Xing $\mathrm{D}$, Chen $\mathrm{Q}$. New insights of mitochondria reactive oxygen species generation and cell apoptosis induced by low dose photodynamic therapy. Eur J Cancer. 2011;47:2750-61.

45. Zhang E, Luo S, Tan X, Shi C. Mechanistic study of IR-780 dye as a potential tumor targeting and drug delivery agent. Biomaterials. 2014;35:771-8.

46. Dosio F, Arpicco S, Stella B, Fattal E. Hyaluronic acid for anticancer drug and nucleic acid delivery. Adv Drug Deliv Rev. 2016;97:204-36.

47. Zhang H, Zhang X, Ren Y, Cao F, Hou L, Zhang Z. An in situ microenvironmental nano-regulator to inhibit the proliferation and metastasis of 4T1 tumor. Theranostics. 2019;9:3580-94.

48. Alushin GM, Lander GC, Kellogg EH, Zhang R, Baker D, Nogales E. Highresolution microtubule structures reveal the structural transitions in aß-tubulin upon GTP hydrolysis. Cell. 2014;157:1117-29.

49. Chen J, Zhang R, Tao C, Huang X, Chen Z, Li X, et al. CuS-NiS, nanomaterials for MRI guided phototherapy of gastric carcinoma via triggering mitochondria-mediated apoptosis and MLKL/CAPG-mediated necroptosis. Nanotoxicology. 2020;14:774-87.

50. Tan KO, Fu NY, Sukumaran SK, Chan SL, Kang JH, Poon KL, et al. MAP-1 is a mitochondrial effector of Bax. Proc Natl Acad Sci U S A. 2005;102:14623-8.

51. Robey RB, Hay N. Mitochondrial hexokinases, novel mediators of the antiapoptotic effects of growth factors and Akt. Oncogene. 2006;25:4683-96.

52. Nogueira V, Park Y, Chen CC, Xu PZ, Chen ML, Tonic I, et al. Akt determines replicative senescence and oxidative or oncogenic premature senescence and sensitizes cells to oxidative apoptosis. Cancer Cell. 2008;14:458-70.

53. Yao S, Ye J, Yin M, Yu R. DMAMCL exerts antitumor effects on hepatocellular carcinoma both in vitro and in vivo. Cancer Lett. 2020;483:87-97.

54. Ge W, Zhao K, Wang X, Li H, Yu M, He M, et al. iASPP Is an antioxidative factor and drives cancer growth and drug resistance by competing with Nrf2 for Keap1 binding. Cancer Cell. 2017;32:561-73.

55. Chen X, Wu Q, Chen Y, Zhang J, Li H, Yang Z, et al. Diosmetin induces apoptosis and enhances the chemotherapeutic efficacy of paclitaxel in non-small cell lung cancer cells via Nrf2 inhibition. Br J Pharmacol. 2019;176:2079-94.

56. Duan FG, Wang MF, Cao YB, Li D, Li RZ, Fan XX, et al. MicroRNA-421 confers paclitaxel resistance by binding to the KEAP1 $3^{\prime} U T R$ and predicts poor survival in non-small cell lung cancer. Cell Death Dis. 2019;10:821.

57. Tsujii M, DuBois RN. Alterations in cellular adhesion and apoptosis in epithelial cells overexpressing prostaglandin endoperoxide synthase 2. Cell. 1995;83:493-501.

58. Janakiraman H, House RP, Talwar S, Courtney SM, Hazard ES, Hardiman $G$, et al. Repression of caspase-3 and RNA-binding protein HuR cleavage by cyclooxygenase- 2 promotes drug resistance in oral squamous cell carcinoma. Oncogene. 2017:36:3137-48.

59. Dery MC, Asselin E. oxytocin upregulates COX-2 and BCL-XL expression through the PI 3-K/Akt signaling pathway. Cancer Res. 2006;66:999-1000.

60. Tsujii M, Kawano S, DuBois RN. Cyclooxygenase-2 expression in human colon cancer cells increases metastatic potential. Proc Natl Acad Sci U S A. 1997;94:3336-40.

61. Yu XJ, Sun K, Tang XH, Zhou CJ, Sun H, Yan Z, et al. Harmine combined with paclitaxel inhibits tumor proliferation and induces apoptosis through down-regulation of cyclooxygenase-2 expression in gastric cancer. Oncol Lett. 2016;12:983-8.

62. Hendrickx N, Volanti C, Moens U, Seternes OM, Witte P, Vandenheede JR, et al. Up-regulation of cyclooxygenase-2 and apoptosis resistance by p38 MAPK in hypericin-mediated photodynamic therapy of human cancer cells. J Biol Chem. 2003;278:52231-9.

63. Etienne-Manneville S. Microtubules in cell migration. Annu Rev Cell Dev Biol. 2013:29:471-99.

64. Jiang Q, Liu Y, Guo R, Yao X, Sung S, Pang Z, et al. Erythrocyte-cancer hybrid membrane-camouflaged melanin nanoparticles for enhancing photothermal therapy efficacy in tumors. Biomaterials. 2019;192:292-308.
65. Hu CM, Zhang L, Aryal S, Cheung C, Fang RH, Zhang L. Erythrocyte membrane-camouflaged polymeric nanoparticles as a biomimetic delivery platform. Proc Natl Acad Sci U S A. 2011;108:10980-5.

66. Hong C, Liang J, Xia J, Zhu Y, Guo Y, Wang A, et al. One stone four birds: a novel liposomal delivery system multi-functionalized with ginsenoside Rh2 for tumor targeting therapy. Nano-Micro Lett. 2020. https://doi.org/ 10.1007/s40820-020-00472-8.

67. Schöttler S, Becker G, Winzen S, Steinbach T, Mohr K, Landfester K, et al. Protein adsorption is required for stealth effect of poly(ethylene glycol)- and poly(phosphoester)-coated nanocarriers. Nat Nanotechnol. 2016;11:372-7.

68. Papi M, Caputo D, Palmieri V, Coppola R, Palchetti S, Bugli F, et al. Clinically approved PEGylated nanoparticles are covered by a protein corona that boosts the uptake by cancer cells. Nanoscale. 2017;9:10327-34.

69. Bigdeli A, Palchetti S, Pozzi D, Hormozi-Nezhad MR, Baldelli Bombelli F, Caracciolo G, et al. Exploring cellular interactions of liposomes using protein corona fingerprints and physicochemical properties. ACS Nano. 2016:10:3723-37.

70. Tuxworth RI, Weber I, Wessels D, Addicks GC, Soll DR, Gerisch G, et al. A role for myosin VII in dynamic cell adhesion. Curr Biol. 2001;11:318-29.

71. Ren X, Zheng R, Fang X, Wang X, Zhang X, Yang W, et al. Red blood cell membrane camouflaged magnetic nanoclusters for imaging-guided photothermal therapy. Biomaterials. 2016;92:13-24.

72. Zhu G, Wang K, Qin H, Zhao X, Chen W, Xu L, et al. Internal cross-linked polymeric nanoparticles with dual sensitivity for combination therapy of muscle-invasive bladder cancer. J Nanobiotechnol. 2020;18:124.

73. Yang Z, Wang J, Ai S, Sun J, Mai X, Guan W. Self-generating oxygen enhanced mitochondrion-targeted photodynamic therapy for tumor treatment with hypoxia scavenging. Theranostics. 2019;9:6809-23.

74. Zhang G, Cheng W, Du L, Xu C, Li J. Synergy of hypoxia relief and heat shock protein inhibition for phototherapy enhancement. J Nanobiotechnol. 2021;19:9.

75. Phua SZF, Yang G, Lim WQ, Verma A, Chen H, Thanabalu T, et al. CatalaseIntegrated Hyaluronic Acid as Nanocarriers for Enhanced Photodynamic Therapy in Solid Tumor. ACS Nano. 2019;13:4742-51.

76. Walker FE. Paclitaxel (TAXOL): side effects and patient education issues. Semin Oncol Nurs. 1993;9:6-10.

77. Straubinger RM, Sharma A, Murray M, Mayhew E. Novel taxol formulations: taxol-containing liposomes. J Natl Cancer Inst Monogr. 1993;15:69-78

78. Fang RH, Kroll AV, Gao W, Zhang L. Cell membrane coating nanotechnology. Adv Mater. 2018;30:e1706759.

79. Zhang Y, Xia Q, LiY, He Z, Li Z, Guo T, et al. CD44 assists the topical antipsoriatic efficacy of curcumin-loaded hyaluronan-modified ethosomes: a new strategy for clustering drug in inflammatory skin. Theranostics. 2019;9:48-64.

80. Zou Y, Liu Y, Yang Z, Zhang D, Lu Y, Zheng M, et al. Effective and targeted human orthotopic glioblastoma xenograft therapy via a multifunctional biomimetic nanomedicine. Adv Mater. 2018;30:e1803717.

\section{Publisher's Note}

Springer Nature remains neutral with regard to jurisdictional claims in published maps and institutional affiliations.
Ready to submit your research? Choose BMC and benefit from:
- fast, convenient online submission
- thorough peer review by experienced researchers in your field
- rapid publication on acceptance
- support for research data, including large and complex data types
- gold Open Access which fosters wider collaboration and increased citations
- maximum visibility for your research: over 100M website views per year

At BMC, research is always in progress.

Learn more biomedcentral.com/submissions 